\title{
Decadal variations and trends in tropical Pacific sea surface salinity since 1970
}

\author{
Thierry Delcroix, ${ }^{1}$ Sophie Cravatte, ${ }^{1}$ and Michael J. McPhaden ${ }^{2}$ \\ Received 5 July 2006; revised 5 October 2006; accepted 18 October 2006; published 17 March 2007.
}

[1] The dominant mode of variability in the tropical Pacific is the interannual

El Niño-Southern Oscillation phenomenon. More subtle variations are also evident on decadal timescales reminiscent of the Pacific Decadal Oscillation (PDO). These variations are superimposed on trends that are possibly linked to global climate change. A major impediment for assessing this decadal and longer timescale variability is the shortness of instrumental records. Near-surface salinity has not yet been systematically analyzed for this reason. This article documents and interprets 1970-2003 observed tropical Pacific sea surface salinity (SSS) changes. Given the time/space SSS data availability, the analysis focuses on changes in three key regions, the western Pacific Warm Pool (WP), the South Pacific Convergence Zone (SPCZ), and the Equatorial Cold Tongue (ECT). A PDO-like signal shows up in these three regions, with some shifts in SSS appearing around the mid-1970s, mid-1990s, and to a lesser extent in 1989-1990. In addition, a clear freshening trend of the order of 0.1 to 0.3 psu per 30 years appears in the WP, SPCZ, and ECT, together with an extension of the low-salinity water surface in the WP and SPCZ. On the basis of available precipitation (P) and evaporation (E) products, and on a survey of the published literature, the PDO-like SSS changes are found to be qualitatively consistent with $\mathrm{P}$ and $\mathrm{E}$ and/or horizontal and vertical salt advection in the WP and the SPCZ. The repercussions and unsolved issues regarding the SSS decadal changes and freshening trends are discussed.

Citation: Delcroix, T., S. Cravatte, and M. J. McPhaden (2007), Decadal variations and trends in tropical Pacific sea surface salinity since 1970, J. Geophys. Res., 112, C03012, doi:10.1029/2006JC003801.

\section{Introduction}

[2] The most energetic climatic signal of the tropical Pacific is the ENSO (El Niño-Southern Oscillation) phenomenon with periods of approximately 3-5 years [Philander, 1990]. Energetic climate variability has also recently been observed at lower frequencies than ENSO. Detection of this low-frequency variability has been made possible through the growing length of physical and biological time series data [Mantua et al., 1997; Mantua and Hare, 2002], careful statistical reconstruction of time series from unevenly distributed observations [Rayner et al., 2003; Smith and Reynolds, 2003; Levitus et al., 2000], and information from proxy data such as tree rings [Mann et al., 1999; Evans et al., 2001] and coral skeletons [Corrège et al., 2004]. Low-frequency change in the Pacific has also been observed in forced and coupled model simulations [e.g., Latif, 1998]. On the basis of these complementary approaches, it has been possible to define the Pacific Decadal Oscillation (PDO) [Hare, 1996], the Interdecadal

\footnotetext{
${ }^{1}$ UMR 5566, Laboratoire d'Etudes en Géophysique et Océanographic Spatiales, Institut de Recherche pour le Développement, Toulouse, France.

${ }^{2}$ Pacific Marine Environmental Laboratory, NOAA, Seattle, Washington, USA.
}

Copyright 2007 by the American Geophysical Union. 0148-0227/07/2006JC003801
Pacific Oscillation (IPO) [Power et al., 1999], the quasidecadal oscillation [Mann and Park, 1994] and the bidecadal oscillation [Minobe et al., 2002]. The degree to which these phenomena are independent versus manifestations of the same underlying physical processes is a matter of debate, but there is clearly energy at decadal timescales spanning both high and low latitudes in the Pacific (see Tourre et al. [2001] for a description of the spatial patterns and tropical phasing associated with these low-frequency changes in sea surface temperature (SST) and sea level pressure).

[3] Tropical Pacific climate changes may also be interpreted as abrupt shifts rather than as quasiperiodic lowfrequency oscillations. For the last century, these shifts were evident in the mid-1920s, mid-1940s, mid-1970s, at the end of the 1980s, and in the mid-1990s [Nitta and Yamada, 1989; Trenberth, 1990; Mantua et al., 1997; Hare and Mantua, 2000; McPhaden and Zhang, 2002; Chavez et al., 2003; Deser et al., 2004]. Interestingly, these shifts in physical conditions, at times observed globally [Yasunaka and Hanawa, 2005], were sometimes detected first from drastic fish or bird population fluctuations [Mantua et al., 1997; Chavez et al., 2003; Lehodey et al., 2003; Peterson and Schwing, 2003]. Superimposed on ENSO, lowerfrequency variability, and abrupt regime shifts is the global change signal that clearly shows up in SST [Cane et al., 
1997], heat content [Levitus et al., 2000] and sea level [Cabanes et al., 2001].

[4] While physics of ENSO is relatively well understood [Wang and Picaut, 2004], the mechanisms responsible for low-frequency oscillations and abrupt shifts are still widely debated [e.g., Gu and Philander, 1997; Kleeman et al., 1999; Knutson and Manabe, 1998; Timmermann and Jin, 2002; Pierce et al., 2002]. Moreover, their links with ENSO are controversial. For example, the question remains as to whether low-frequency changes induce ENSO modulations, e.g., by modifying the mean state of the tropical Pacific [Fedorov and Philander, 2000; Wang and An, 2002], or whether the nonsymmetric character of El Niño and La Niña leaves a residual which shows up as low-frequency changes [Timmermann and Jin, 2002, 2003; Rodgers et al., 2004b]. In the latter case, low-frequency variability would result from ENSO physics, and not from mechanisms intrinsic to low-frequency variability [Cane and Evans, 2000]. This would explain the fair agreement (see section 3) between the Southern Oscillation Index [Trenberth, 1984], often used to classify the tropical Pacific as being either in an El Niño or La Niña state, and the PDO index [Mantua et al., 1997], often used to classify the Pacific north of $20^{\circ} \mathrm{N}$ as being either in a positive or negative phase of the PDO. Whatever the case, the obvious climate imprints of ENSO, low-frequency oscillations, abrupt shifts and/or long-term trend all need to be considered if one wants to correctly assess our changing environment and the socioeconomic impacts of climate variability [Glantz, 1996; Goddard and Dilley, 2005]. The assessment of such imprints will further help us in separating the natural variability from the anthropogenic climate change.

[5] The sustained observing system established by international TOGA [World Climate Research Program, 1985] program and maintained afterward has proven to be very valuable for monitoring, understanding, and forecasting ENSO variability [McPhaden et al., 1998]. However, historical data sets are much less adequate for studying lowfrequency changes, abrupt shifts and long-term basin-scale trends. In particular, very few studies have addressed changes in salinity, which is important for describing and understanding subduction processes [Dickson et al., 1988], ocean spiciness [Schneider, 2000], mixed-layer depth [Lukas and Lindstrom, 1991], barrier layer thickness [Delcroix and McPhaden, 2002], sea level [Maes, 1998], current and temperature structures [Huang et al., 2005], and the hydrological cycle [Curry et al., 2003] on decadal timescales. Among those studies that have focused on decadal salinity variations in the Pacific, Overland and Salo [1999] found consistent changes between sea surface salinity (SSS) and precipitation (P) before and after the mid-1970s regime shift. That study focused on three sites only in the NE Pacific. Lukas [2001] noted a 1991-1997 near-surface salinity freshening at the HOT (Hawaii Ocean Time series) station located north of Oahu, Hawaii, with an apparent reversal starting in 1998 possibly associated with the mid-1990s regime shift. Antonov et al. [2002] reported evidence of a 1978-1994 freshening in the upper $3000 \mathrm{~m}$ of the western Pacific warm pool. Boyer et al. [2005], computing linear trends on zonally integrated salinity, documented a freshening within $15^{\circ} \mathrm{S}-60^{\circ} \mathrm{N}$ in the upper $500 \mathrm{~m}$ and a salinity increase within $20^{\circ} \mathrm{S}-30^{\circ} \mathrm{S}$ in the upper $200 \mathrm{~m}$. Analyses based on coral data provide further relevant information on decadal and long-term trend SSS changes at few isolated locations in the Pacific [Asami et al., 2005; Cobb et al., 2001; Cole et al., 1993; Guilderson and Schrag, 1999; Juillet-Leclerc et al., 2006; Kilbourne et al., 2004; Urban et al., 2000; Linsley et al., 1994, 2006].

[6] As a complement to these earlier studies, this paper attempts to document and analyze SSS variability in the tropical Pacific using a recently compiled data set covering the 1970-2003 period. The rest of the paper is organized as follows. Section 2 describes the in situ SSS data and data processing. Sections 3 and 4 document evidence for decadal variations and long-term trends, respectively, and discuss the possible mechanisms responsible for the observed changes. Discussions and conclusions are presented in section 5 .

\section{Data and Data Processing}

[7] The 1970-2003 SSS data originate from surface samples and ThermoSalinoGraphs (TSG) measurements obtained from voluntary observing ship (VOS) programs, from conductivity/temperature sensors on TAO/TRITON moorings, and to a lesser extent from salinity observations collected during research cruises (Figure 1). Details about the different SSS data sampling characteristics, the time periods they cover, and data processing and quality control procedures can be found in work by Delcroix et al. [2005].

[8] As the SSS data originate from different instruments, the question arises as to how to combine the different data sets, a procedure which is especially critical for the detection of climate shifts and long-term trends. To address this question, Delcroix et al. [2005] relied on statistical comparisons between buckets samples, TSG, mooring and CTD data. As a result, they subtracted 0.1 from all bucket measurements and added 0.02 to all VOS-derived TSG measurements, on the assumption that the biases were stationary in time. In cases where the instrument types could not be documented, no correction was applied. With these caveats, comparison plots of SSS time series at various locations provide confidence in using these constant corrections, in particular because we did not detect an obvious shift in SSS in 1992 at times when bucket samples were replaced by TSG instruments for most regions. In the equatorial cold tongue of the eastern Pacific however, replacement only occurred in late 1996 for the round-theworld merchant ships sampling this region at a time when we observed a sharp regional drop in SSS (see section 3). Since the TSG installed on these ships are less frequently maintained because of the length of the trips between port calls, and since bucket sampling in the engine room for proper TSG calibration were performed for only about $50 \%$ of all transects, the possibility exists that the post-1996 SSS values may be underestimated by $0.1-0.2$ for some voyages. This underestimate can occur because fouling and/or scouring of the TSG conductivity cell yields readings that are biased low. We expect, however, that any low biases are confined to the 1996-1998 period only, because temperature/conductivity sensors providing high temporal resolution were installed on the $95^{\circ} \mathrm{W}$ TAO/TRITON moorings in early 1999 . 


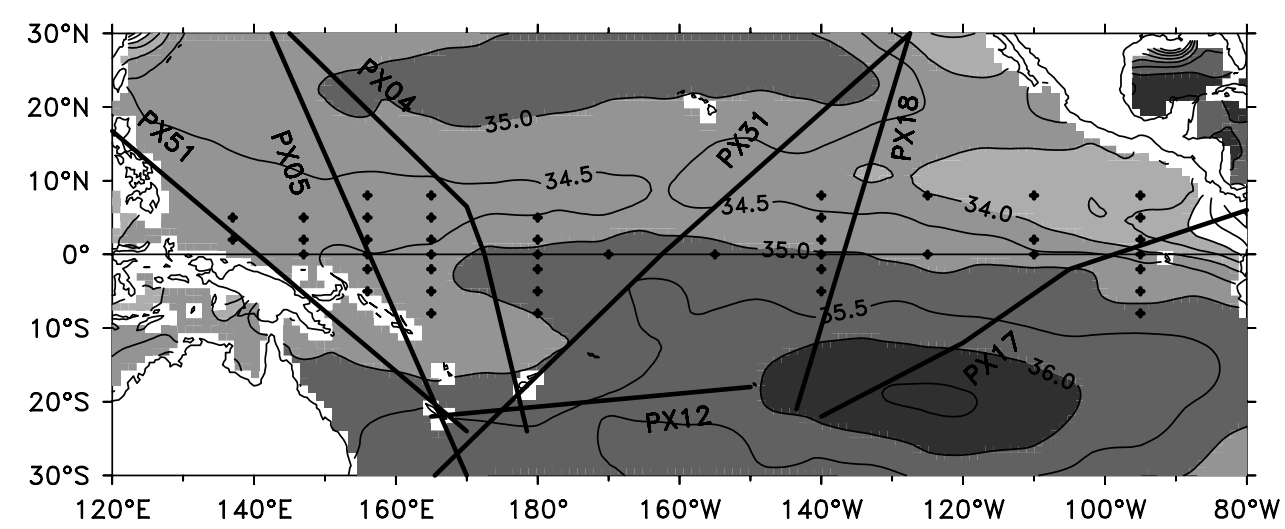

Figure 1. Long-term mean SSS in the tropical Pacific; contour interval is 0.5. Overplotted are the wellsampled shipping lines (PX51, PX05, etc.; heavy black lines) and the TAO/TRITON moorings (black dots) providing SSS observations.

[9] Following Delcroix et al. [2005], and in agreement with their computed decorrelation scales, we gridded the data onto boxes of $10^{\circ}$ longitude, $2^{\circ}$ latitude and 1 month. Figure 2 shows the SSS record lengths in these boxes, as expressed in decades. Time series equal to or in excess to 20 years (a reasonable minimum length to study decadal changes) appear in the western tropical Pacific warm pool (WP), the South Pacific Convergence Zone (SPCZ), and the equatorial cold tongue (ECT). Hereafter, we focus chiefly on these 3 regions. We examine variability at the scale of both the above-noted grid resolution and at a finer grid resolution along the well-sampled PX05, PX12 and PX17 ship tracks. Grid elements were chosen as 1 latitude and 1 month for PX05 and PX17, and $2^{\circ}$ longitude and 1 month for PX12, as in work by Delcroix et al. [2005]. The median (instead of the mean) values of all SSS values within a grid element were then computed to reduce the potential effects of outliers due, for example, to localized shallow fresh water lenses following rainstorms. Finally, data gaps smaller than 3 times the grid element sizes were filled via a Laplacian interpolation scheme [Delcroix and Hénin, 1991].

[10] As a background to the present paper, we note that an overview of the mean, standard deviation and seasonal SSS cycle for all ship tracks (PX51, PX05, PX04, PX12, PX17) crossing our three selected regions can be found in the work of Delcroix et al. [2005]. Also, an analysis of the ENSOrelated SSS signal based on a subset of the present observations for the WP and the SPCZ is given by Delcroix and McPhaden [2002] and Gouriou and Delcroix [2002], respectively. These last two papers show, in particular: (1) the

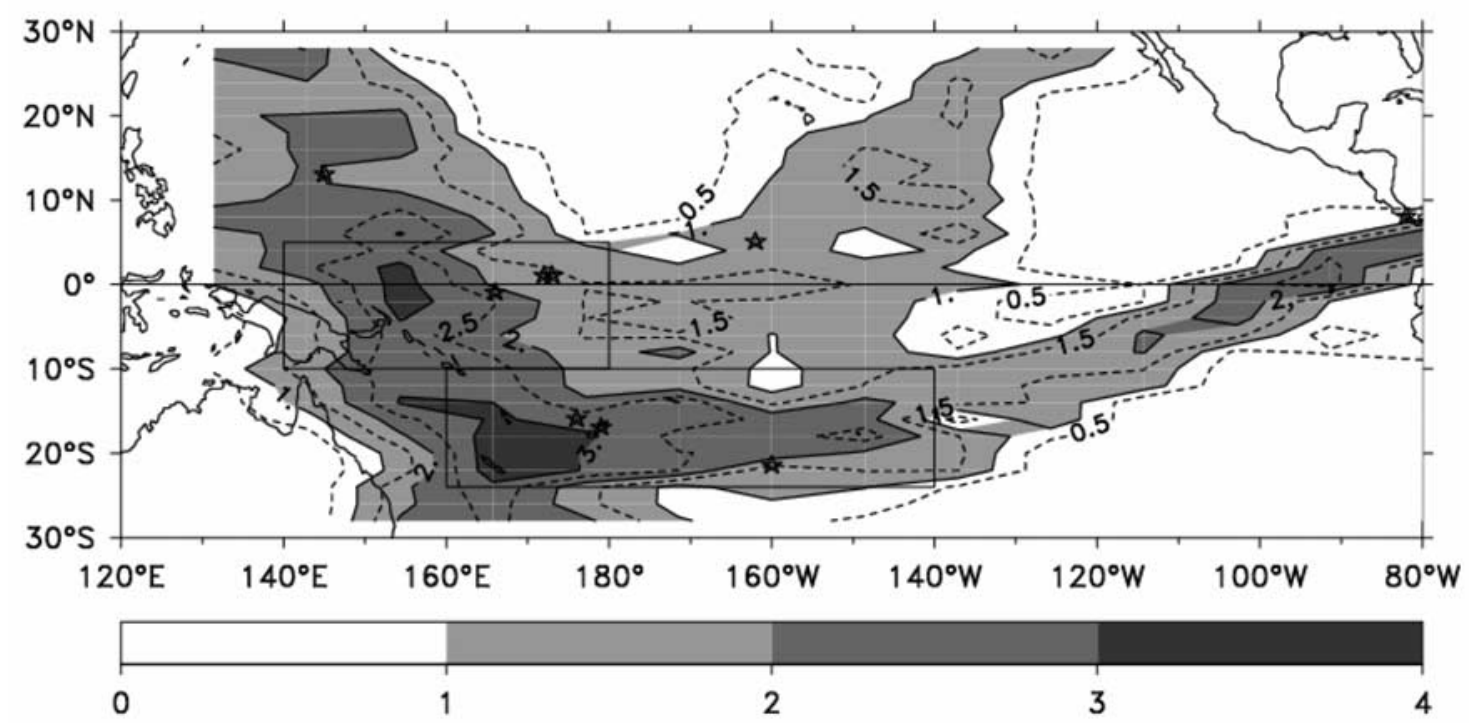

Figure 2. Lengths of SSS time series in $10^{\circ}$ longitude $\times 2^{\circ}$ longitude rectangles, as expressed in decades. The two rectangles $\left(10^{\circ} \mathrm{S}-5^{\circ} \mathrm{N}, 140^{\circ} \mathrm{E}-180^{\circ}\right.$ and $\left.24^{\circ} \mathrm{S}-10^{\circ} \mathrm{S}, 160^{\circ} \mathrm{E}-140^{\circ} \mathrm{W}\right)$ delimit wellsampled regions, and the nine stars represent locations with coral-derived $\delta \mathrm{O}_{18}$ records, as discussed in section 4.2 . 

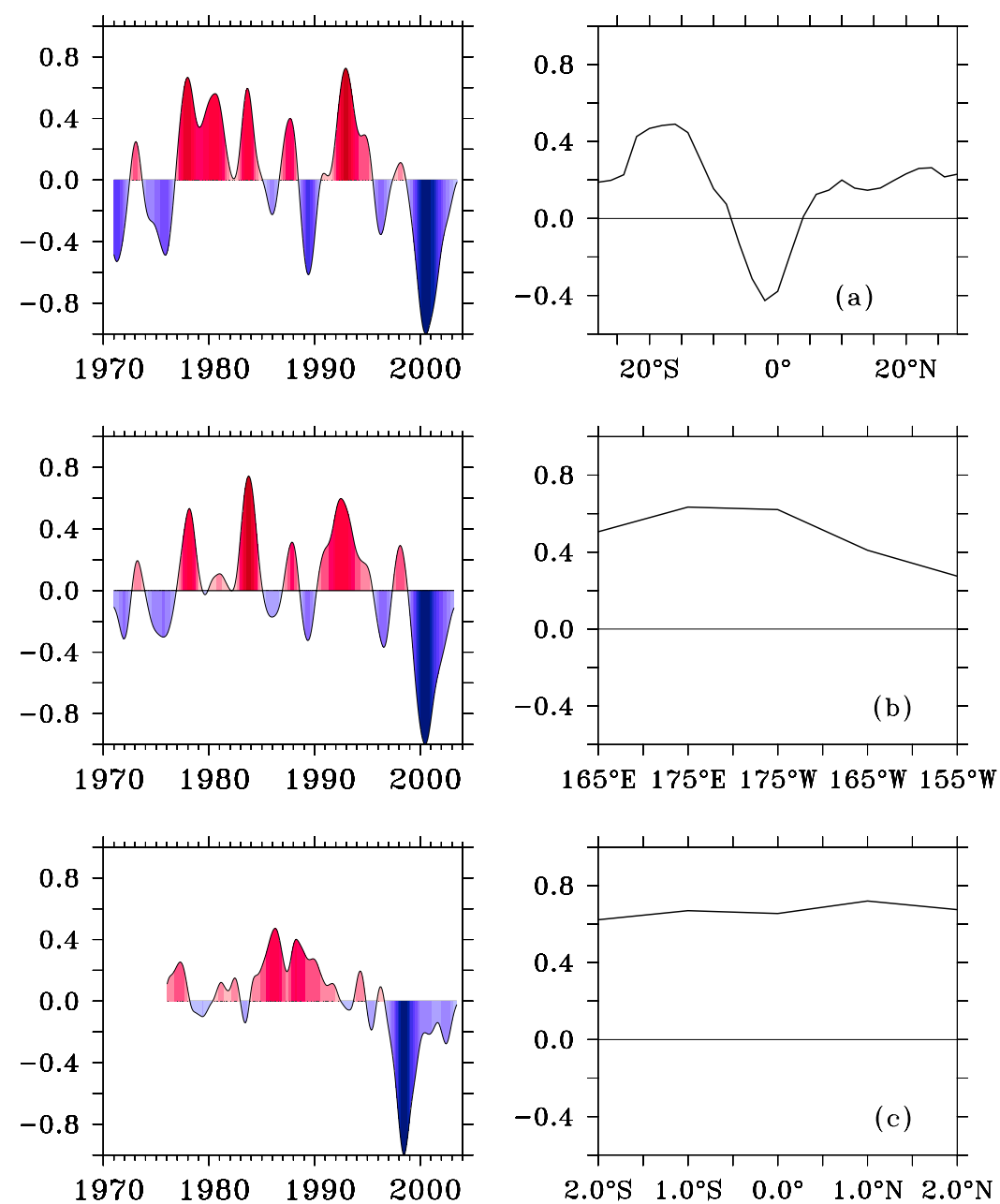

Figure 3. (left) Time functions and (right) spatial patterns of the first EOF for SSS along the (top) PX05, (middle) PX12, and (bottom) PX17 mean shipping lines. Units are defined so that the product between spatial pattern and time function represents psu. Note the different longitude and latitude scales for the spatial patterns.

existence in the equatorial band near the dateline of a zonal SSS front separating the low salinity of the western Pacific warm pool waters from the central Pacific waters, (2) the existence in the southwestern tropical Pacific of a NE-SW oriented front separating the warm pool waters from salty subtropical waters, and (3) the reverse displacements of these fronts at the ENSO timescale, with the equatorial front moving eastward during El Niño and westward during La Niña over several thousands of kilometers.

[11] Additional data are used for the interpretation of SSS changes. They include three different products for precipitation (P): the 1948-2003 Precipitation Reconstruction (PREC) data set product [Chen et al., 2004], the 19792003 CMAP (Climate Prediction Center Merged Analysis of Precipitation) product [Xie and Arkin, 1997], and the 19792003 GPCP (Global Precipitation Climatology Project) product [Adler et al., 2003] which, despite its shorter record length, is more suited to inferring long-term trends [Yin et al., 2004]. Two different products are used for evaporation (E): the 1948-2004 NCEP (National Center for Environment Prediction) product [Kalnay et al., 1996], and the 1948-
2004 ECMWF (European Centre for Medium-Range Weather Forecasts) Re-Analysis product (ERA40). The SST variability is inferred from the HadISST1 product [Rayner et al., 2003].

\section{Decadal SSS Variations}

\subsection{Observed Features}

[12] Values along the well-sampled PX05, PX12 and PX17 ship tracks are first considered. To filter out seasonal variations, SSS variations equal or shorter than one year were first removed by using a 25-month Hanning filter [Blackman and Tukey, 1958]. The spatial patterns and the associated time functions of the first empirical orthogonal functions (EOF) of the filtered SSS are presented in Figures $3 a-3 c$ for the three tracks; they represent $41 \%$, $78 \%$, and $85 \%$ of the low-frequency variance, respectively. The spatial function is roughly a $\mathrm{V}$ shaped pattern in the west along PX05 with values of opposite sign within and outside of the equatorial band; it is close to a straight line with positive values both in the SPCZ (PX12) and in the 

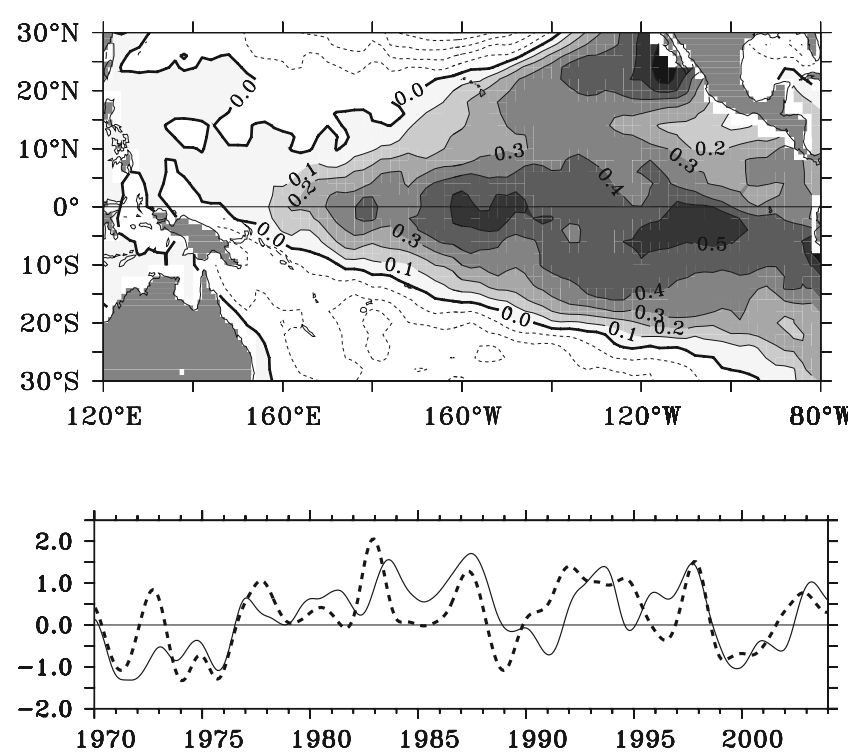

Figure 4. (top) Regression between the 1970-2003 25-month Hanning filtered SST and PDO; contour interval is 0.1 , and shaded areas are positive. (bottom) Time series of 25-month Hanning filtered PDO (solid line) and reversed SOI (dashed line). Units in the top plot are defined so that the product between the contours and the PDO represents ${ }^{\circ} \mathrm{C}$. Note that the PDO is derived as the leading EOF of monthly SST anomalies in the North Pacific Ocean, poleward of $20^{\circ} \mathrm{N}$. Positive values indicate warm phases of the PDO, with a tropical SST signal corresponding to the top plot. A schematic of the SST and wind signature of the PDO, as well as some relevant references, can be found at http://www.jisao.washington.edu/pdo/; see also Mantua and Hare [2002] for a PDO review.

ECT (PX17). The three time functions show interesting features in common with, in particular, an overall tendency for negative values before the mid-1970s and after the mid1990 s, and positive values in between except in 1989-1990 in the west and in the SPCZ. We note that the time function for the ECT starts in 1976 only, preventing us from drawing conclusions about the preceding years and in particular about possible local manifestations of the mid-1970s regime shift. Also, the negative values after the mid-1990s in Figure 3c appear before those in the WP and the SPCZ (Figures 3a and 3b) possibly due to the strong 1997-1998 El Niño (as discussed below).

[13] The EOF functions imply saltier-than-average SSS from about the mid-1970s to the mid-1990s, except for the western equatorial band which experienced fresher-thanaverage SSS during this period. Opposite conditions prevailed before the mid-1970s, in 1989-1990, and after the mid-1990s. Interestingly, the three EOF time functions in Figure 3 correspond well to the PDO index which is also generally negative before the mid-1970s and after the mid1990s, and positive in between except during 1989-1090 (Figure 4). Quantitatively, the best correlations between the two time series are $R=0.61,0.57$, and 0.51 , obtained when the EOF time functions lag behind the PDO by 0 and 2 months for PX05 and PX12, and lead the PDO by 17 months for PX17. (Recall that the time function for
PX17 is not directly comparable to the ones for PX05 and PX12, as it starts after the mid-1970s shift only).

[14] The spatial patterns and the associated time functions of the second EOF (not shown here) show remarkably longterm trends for PX05 and PX12 that will be discussed later. When the time series are first detrended before doing the EOF analysis, the first EOFs are almost unchanged for PX05 and PX12, demonstrating the robustness of the PDO-like signals. The situation is different for the PX17 in the equatorial cold tongue, where detrending the time series first alters the PDO-like signal. This sensitivity reflects the fact that the 1976-2003 time series for PX17 does not include the mid-1970s regime shift, which makes it difficult to separate PDO-like signals and long-term trends via an EOF analysis. It is therefore highly probable that the first EOF of PX17 includes both a long-term trend and a PDOlike signal, which emphasizes the constraints that limited record lengths impose on our ability to draw definitive conclusions about decadal variability.

\subsection{Possible Forcing Factors}

[15] In order to clarify future discussions, the equation relating SSS and the possible forcing factors is first presented. If small-scale mixing processes are ignored, the salinity balance is governed by the simplified equation

$$
\begin{aligned}
\mathrm{dS} / \mathrm{dt} & \left.\left.+\left[(\mathrm{dh} / \mathrm{dt})+\mathrm{w}_{\mathrm{z}=\mathrm{h}}\right)\right] \cdot \mathrm{H}\left[(\mathrm{dh} / \mathrm{dt})+\mathrm{w}_{\mathrm{z}=\mathrm{h}}\right)\right] \cdot\left(\mathrm{S}-\mathrm{S}_{\mathrm{z}=\mathrm{h}}\right) / \mathrm{h} \\
& =(\mathrm{S} / \mathrm{h}) . \quad(\mathrm{E}-\mathrm{P})
\end{aligned}
$$

where $\mathrm{d} / \mathrm{dt}=\partial / \partial \mathrm{t}+\mathrm{u} . \partial / \partial \mathrm{x}+\mathrm{v} . \partial / \partial \mathrm{y}$ is the total derivative including local rate of change $(\partial / \partial \mathrm{t})$ and advective (u. $\partial / \partial \mathrm{x}+$ $\mathrm{v} . \partial / \partial \mathrm{y})$ components, $\mathrm{S}$ is salinity, $\mathrm{h}$ is the depth of the salinity mixed layer, $u$ is the zonal velocity (positive eastward), $v$ is the meridional velocity (positive northward), $\mathrm{W}$ is the vertical velocity (positive upward), and $\mathrm{H}$ is the Heaviside step function having the property that $\mathrm{H}=0$ if $\left.\left[(\mathrm{dh} / \mathrm{dt})+\mathrm{w}_{\mathrm{z}=\mathrm{h}}\right)\right]<0$, otherwise $\mathrm{H}=1$ (entrainment at the base of the mixed layer can increase the mixed-layer salinity, but detrainment cannot.) All terms in the equation can be separated into a fluctuating component (noted $u^{\prime}$ and $v^{\prime}$ for the horizontal velocity), and a time-mean component (noted $U$ and $V$, so that $u=U+u^{\prime}$ and $v=V+v^{\prime}$ ). As we are interested in decadal variability, $u^{\prime}$ and $v^{\prime}$ represent the variations of the velocities at decadal timescales. (For simplicity, this decomposition, developed to qualitatively address potentially important processes, assumes interactions between seasonal cycle and interannual variability with decadal time fluctuations are weak.) Changes in P, E, horizontal and vertical advection that could affect SSS changes at the PDO timescales are now examined.

\subsubsection{Precipitation}

[16] Figure 5 shows the regression coefficients between the 1970-2003 PDO index in Figure 4 and P changes derived from the PREC product. A comparable result applies for the period 1950-2003 and for the GPCP product during 1979-2003. Negative values (dashed contours) in Figure 5 reflect below average $\mathrm{P}$ during positive phases of the PDO, and positive values (thin contours) above average $\mathrm{P}$ during positive phases of the PDO. When PX05 and PX12 are superimposed on Figure 5, a fair agreement is observed between the locations of below average P and saltier-than- 




Figure 5. Regression between the 1970-2003 25-month Hanning filtered PREC precipitation product and the PDO; contour interval is 0.2 , and shaded areas are positive. Units are defined so that the product between the contour values and the PDO (as shown in Figure 4) represents $\mathrm{mm} / \mathrm{d}$. Overplotted as thick black lines are the PX05, PX12, and PX17 shipping lines.

normal SSS, and vice versa, depending on the positive or negative phases of the PDO. For example, the positive PDO period from the mid-1970s to mid-1990s is qualitatively consistent with below average $\mathrm{P}$ and saltier-than-average SSS for PX12 and the off-equatorial part of PX05. The question remains as to whether or not the rainfall changes associated with the PDO could quantitatively account for the SSS changes. To answer this question, we perform the following simple order of magnitude calculations. At $15^{\circ} \mathrm{S}$ along PX05, a linear decrease of rainfall anomalies from $+0.5 \mathrm{~mm} / \mathrm{d}$ in 1975 ( -0.5 in Figure 5 multiplied by -1 for the PDO in Figure 4) to $-0.25 \mathrm{~mm} / \mathrm{d}$ in $1977(-0.5$ in Figure 5 multiplied by 0.5 for the PDO in Figure 4) would result in a $274 \mathrm{~mm}$ freshwater deficit over a 2 -year period. This decrease would induce a rise in SSS of 0.27 assuming a local balance of $S_{t}=-(S / h) P$ where the mixed-layer depth $h=35 \mathrm{~m}$. Looking at the PX05 EOF functions in Figure $3 \mathrm{a}$, the SSS anomalies rise from -0.16 in 1975 ( -0.4 for the time function in 1975 multiplied by 0.4 at $\left.15^{\circ} \mathrm{S}\right)$ to +0.16 in $1977(+0.4$ for the time function in 1977 multiplied by 0.4 at $15^{\circ} \mathrm{S}$ ) which implies a rise of 0.32 over the 2-year period. Though admittedly crude, this calculation and similar ones for different locations along the PX05 and PX12 tracks suggest that the PDO-related P changes would be sufficient to quantitatively account for a significant part of the observed SSS changes in Figures $3 \mathrm{a}$ and $3 \mathrm{~b}$ In contrast, for the ECT (PX17), an obvious disagreement shows up between $\mathrm{P}$ and SSS changes as positive (negative) PDO periods with above (below) average $P$ are inconsistently associated with saltier-than-normal (fresher-thannormal) SSS. The amplitude of the $\mathrm{P}$ changes linked to the PDO is moreover quite small in the ECT according to Figure 5.

\subsubsection{Evaporation}

[17] The regression coefficients (not shown here) between the 1970-2003 PDO index versus the NCEP and ERA40 evaporation products are, on average, about $1 / 3$ of the $\mathrm{P}$ changes shown in Figure 5. Also, the sign of the coefficients derived from the two products are overall inconsistent with one another, except in the SW tropical Pacific. In that region, encompassing the western part of PX12 and the southern part of PX05, the regression coefficients are of opposite sign from those in Figure 5, meaning that E and minus $\mathrm{P}$ combine constructively to change SSS on PDO timescales. There, the arguments developed above for $\mathrm{P}$ thus actually apply for $\mathrm{P}-\mathrm{E}$, with $\mathrm{P}$ accounting for about $75 \%$ of $\mathrm{P}-\mathrm{E}$ changes.

\subsubsection{Horizontal Advection}

[18] Modifications of SSS along the three tracks at PDO timescales could further result from variations in salinity transport, due to either changes in the horizontal surface currents $\left(u^{\prime} . S_{x}\right.$ or $\left.v^{\prime} . S_{y}\right)$ or changes in the horizontal SSS gradients $\left(U . S_{x}^{\prime}\right.$ or $\left.V . S_{y}^{\prime}\right)$. The observations do not allow us to directly assess this mechanism on PDO timescales. However, the following qualitative discussion based on a synthesis of information gathered in the published literature is instructive.

\subsubsection{Western Equatorial Pacific (Equatorial Part of PX05)}

[19] As noted by Picaut et al. [2001], from 1973-1995, the only time when the eastern edge of the western Pacific warm pool between $4^{\circ} \mathrm{N}-4^{\circ} \mathrm{S}$ was located west of $150^{\circ} \mathrm{E}$ was prior to 1976 . For this 1973-1995 time period, these authors demonstrated that zonal advection on ENSO timescales appears to be the dominant mechanism for the displacement of the eastern edge of the warm pool, to the west of which is found relatively fresh surface water. Delcroix and Picaut [1998] reached the same conclusion regarding advection over the 1987-1988 period, indicating in particular that zonal salt advection was mainly influenced by the changes in zonal current $\left(u^{\prime} . S_{x}\right)$ rather than that of zonal salinity gradient $\left(U . S_{x}^{\prime}\right)$. More recently, Maes et al. [2004] for the 1992-2001 period established that the eastern edge of the warm pool averaged between $2^{\circ} \mathrm{N}-2^{\circ} \mathrm{S}$ reached its westernmost location during the end of the 1990s, in response to anomalous zonal advection. Collectively, these results are consistent with the 1970-2003 SSS changes we found for the equatorial part of PX05 and suggest that anomalous westward (eastward) advection of high (low) salinity waters contributes to SSS variability in that region on PDO timescales.

\subsubsection{SPCZ (Southern Part of PX05 and PX12)}

[20] As mentioned in section 2, Gouriou and Delcroix [2002] pointed out that over the 25 year period 1976-2000, the southwestern salinity front located in the SPCZ moved in the opposite direction as the equatorial front. They also noted that the displacements of the SPCZ front follow the sign of geostrophic current anomalies derived from GEOSAT (1987-1988) and TOPEX/Poseidon (19932000), as well as shifts in the region of high precipitation associated with the warmest SST. While there may be some ambiguities in assuming these results apply to our entire study period, the arguments developed above for the WP, the contrasting displacements of the two fronts on ENSO timescales, and the excellent phasing of the PX12 and PX05 EOF time functions suggest that horizontal advection is partly responsible for the occurrence of saltier-than-normal 
(fresher-than-normal) waters in the south western tropical Pacific during positive (negative) PDO periods.

\subsubsection{Northern Part of PX05}

[21] Qiu and Joyce [1992] and Deser et al. [1999] analyzed the 1969-1988 geostrophic transport of the Kuroshio Current south of Japan, and found a smaller transport before the mid 1970s during the negative phase of the PDO. On the basis of the 1993-2001 TOPEX/Poseidon sea level measurements, Chavez et al. [2003] inferred a reduced geostrophic component of the Kuroshio Current after 1997-1998, likewise during a negative phase of the PDO. The mean SSS along PX05 shows a negative SSS gradient of about $S_{y}=-0.35$ psu per $1000 \mathrm{~km}$ poleward of $22^{\circ} \mathrm{N}$ [see Delcroix et al., 2005, Figure 4]. Thus reduced (enhanced) advection of high-salinity waters by anomalous surface current $\left(v^{\prime} . S_{y}\right)$ would tend to generate below (above) normal SSS in the northern part of PX05 during the negative (positive) phase of the PDO, as is observed in Figure 3. The surface current changes that would be needed to account for the SSS changes at the PDO timescale can be estimated assuming a local balance of $S_{t}=-v^{\prime} \cdot S_{y}$. From the PX05 EOF functions in Figure 3a, SSS anomalies rise from -0.08 in $1975(-0.4$ for the time function in 1975 multiplied by 0.2 at $\left.25^{\circ} \mathrm{N}\right)$ to +0.08 in $1977(+0.4$ for the time function in 1977 multiplied by 0.2 at $25^{\circ} \mathrm{N}$ ), which implies a rise of 0.16 over the 2-year period running from mid-1975 to mid-1977. Using the $S_{y}$ value above, this SSS rise would correspond to an increase of the Kuroshio of the order of $7 \mathrm{~cm} \mathrm{~s}^{-1}$ over the 2-year period. This order of magnitude change is quite reasonable, suggesting that changes in the Kuroshio Current on the PDO timescales could contribute to changes in SSS in the northern part of PX05 via salt advection. Interestingly, these current changes are qualitatively consistent with the basin-scale circulation changes that would result from $\mathrm{E}-\mathrm{P}$ anomalies observed in the western half of the basin during different phases of the PDO [see Huang et al., 2005]. The SSS changes in the northern part of PX05 could therefore be induced both by direct local (see the second paragraph in section 3.2) and indirect remote effects of $\mathrm{E}-\mathrm{P}$ anomalies on ocean circulation.

\subsubsection{Eastern Equatorial Cold Tongue (Equatorial} Part of PX17)

[22] The mean spatial distribution of SSS exhibits a well-marked ESE-WNW salinity front $\left(S_{x}, S_{y}\right)$ in the eastern equatorial Pacific (Figure 1). Along PX17, this SSS gradient leads to changes of about $1.2 \mathrm{psu}$ between $1^{\circ} \mathrm{N}$ and $1^{\circ} \mathrm{S}$ [Delcroix et al., 2005, Figure 5c]. Slight displacements of that front in the zonal and/or meridional directions could thus strongly impact SSS values in the equatorial part of PX17. However, changes in the surface circulation $\left(u^{\prime}, v^{\prime}\right)$ are poorly known at seasonal-tointerannual timescales in the eastern Pacific [Kessler, 2006], and so understandably largely unknown on PDO timescales. Thus it is not possible to assess the possible role of horizontal advection in accounting for the SSS changes shown in Figure $3 \mathrm{c}$.

\subsubsection{Vertical Advection}

[23] The possible contribution of vertical advection is most relevant for the equatorial parts of PX05 and PX17, so we concentrate on these transects only. Analyses of observations indicate changes in mean thermocline depth (averaged over 5 to 10 years) before and after the mid1970 s, i.e., during a negative and positive phase of the PDO. The thermocline was inferred to be deeper in the western equatorial Pacific before the mid-1970s, and slightly shallower in the eastern equatorial Pacific [Guilderson and Schrag, 1998; Wang and An, 2001; McPhaden and Zhang, 2002]. These changes suggest that equatorial upwelling penetrated farther to the west during negative PDO periods. Such a situation is observed during La Niña period when a "chimney" of high-salinity waters in the upper $100 \mathrm{~m}$ shows up in the equatorial band [see Delcroix and Picaut, 1998, Figure 4b]. Upwelling would bring high-salinity water to the surface, in accordance with our observations showing above- average SSS in the equatorial part of PX05. Similar reasoning would suggest that for the equatorial part of PX17, enhanced upwelling during negative PDO would result in above-normal SSS, which is not observed in our data.

[24] While notable differences show up for the amplitude of the thermocline depth anomalies between the abovenoted observational and various modeling studies [see Chang et al., 2001; Wang and An, 2001, 2002; Karspeck and Cane, 2002], they all conclude that there is an increase (decrease) in the zonal slope of the thermocline along the equator during negative (positive) PDO periods. The Equatorial Undercurrent (EUC) velocity is to first-order proportional to the thermocline slope [McCreary, 1981; McPhaden, 1981; Yu and McPhaden, 1999] and modeled EUC transports weaken after the mid-1970s [Rodgers et al., 2004a]. Thus an alternative hypothesis for the ECT is that the import of high-salinity water changed because of anomalous EUC transport variations $\left(u^{\prime} \cdot S_{x}\right)$. This would imply higher-than-normal SSS during negative PDO phases in the ECT which, however, is at odds with our observations. Another possibility is the occurrence of PDO-related anomalous salinity water at the EUC source $\left(u . S_{x}^{\prime}\right)$, possibly associated with the advection of spiciness anomalies subducted at $20^{\circ}$ to $30^{\circ} \mathrm{S}$ in the eastern-central part of the Pacific [see McCreary and Lu, 1994; Kessler, 1999; Schneider, 2000; Bratcher and Giese, 2002; Giese et al., 2002]. While we have no way to assess a possible spiciness anomaly pathway, a detailed examination of recently compiled CTD casts at $165^{\circ} \mathrm{E}-170^{\circ} \mathrm{E}$ (S. Cravatte et al., Observed subsurface salinity changes in the south tropical Pacific since 1950, manuscript in preparation, 2007), the best sampled longitudes in the western equatorial Pacific, reveals that salinity at the EUC level was saltier before the mid-1970s [e.g., Hisard et al., 1969] and after the mid1990s [e.g., Eldin et al., 2004] than during the mid-1970s to mid-1990s [e.g., Delcroix and Eldin, 1995]. This would imply higher-than-normal SSS during negative PDO phases in the ECT, which likewise conflicts with our observations.

[25] To sum up, the timing of PDO-related SSS changes revealed by the EOF analysis appears to be qualitatively consistent with $\mathrm{E}-\mathrm{P}$, horizontal and/or vertical advection for PX05 and PX12. The equatorial part of PX17 is the only place where no qualitative explanation was found to account for the SSS changes. Quantitatively, the notable discrepancies in $\mathrm{P}$ and $\mathrm{E}$ products, the absence of long time series for surface currents, and the lack of information about the 
$25^{\circ} \mathrm{N}-27^{\circ} \mathrm{N} ; 140^{\circ} \mathrm{E}-150^{\circ} \mathrm{E}$
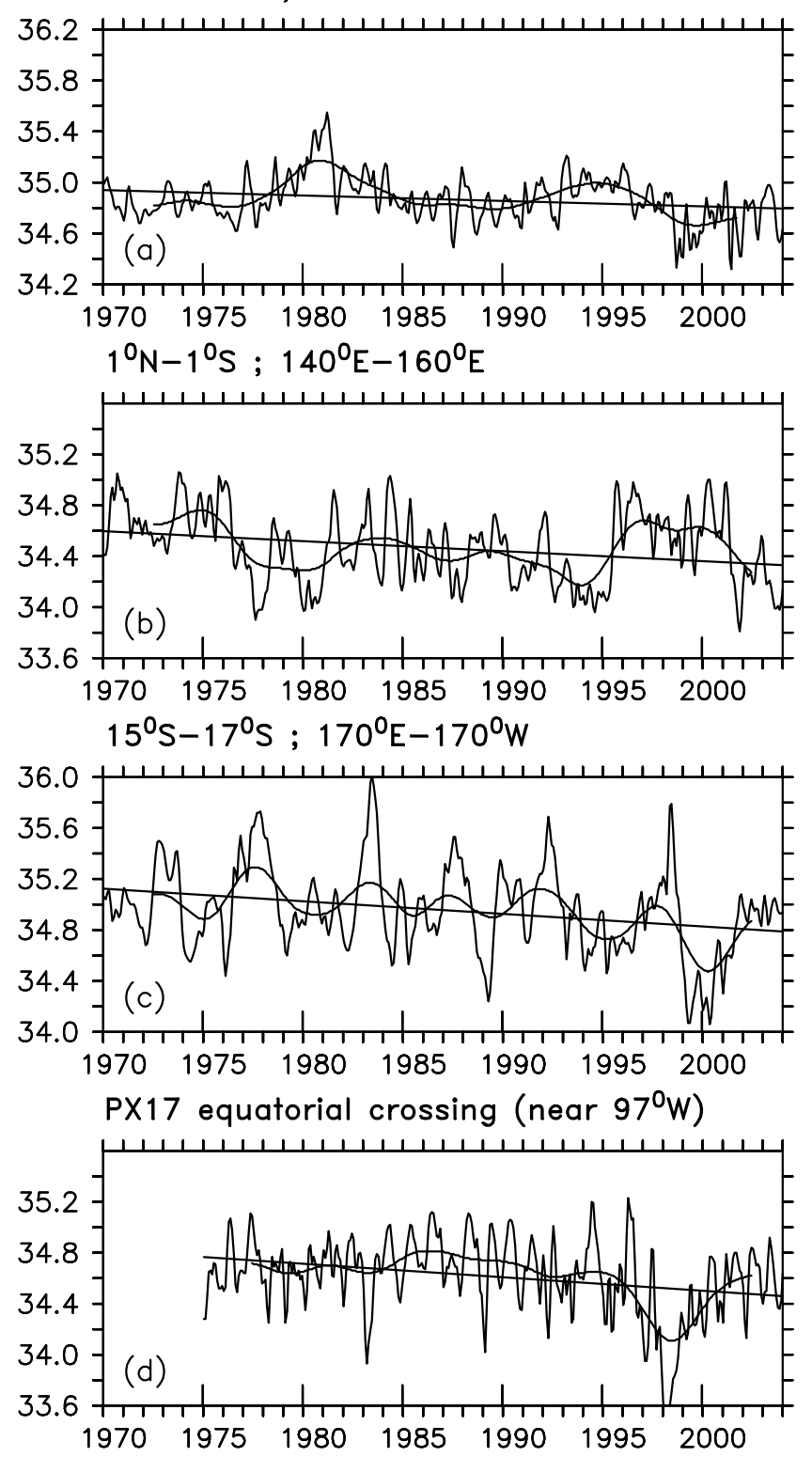

Figure 6. Time series of monthly SSS values at reported locations. The low-frequency curves represent the 61-month Hanning filtered values used to highlight SSS changes at periods longer than the ENSO timescales. The straight lines represent the linear least squares fits of the monthly values used to quantify linear trends.

depth of the salinity mixed layer all prevent us drawing more robust conclusions.

\section{Long-Term Trends}

\subsection{Observed Features}

[26] The 1970-2003 time series of monthly values in SSS averaged over four well-sampled regions located in the northern, equatorial and southern parts of the western tropical Pacific and in the ECT are shown in Figure 6. Aside from the seasonal and ENSO variability described in previous papers (see section 2), the decadal timescale variations extracted by the EOF analysis described above are also evident in the raw monthly data. For example, in the western equatorial Pacific region $\left(1^{\circ} \mathrm{N}-1^{\circ} \mathrm{S}, 140^{\circ} \mathrm{E}-\right.$ $160^{\circ} \mathrm{E}$ ), there is an overall tendency for higher-than-average SSS before the mid-1970s and after the mid-1990s as well as below average SSS from the mid-1970s to the mid1990s.

[27] Our interest in Figure 6 for this discussion though is the remarkable long-term downward trends that appear in the four regions. To quantify these trends, a simple linear regression analysis was performed on each time series, yielding values of $-0.12,-0.23,-0.29$ and $-0.32 \mathrm{psu}$ per 30 years for the northern, equatorial and southern parts of the western tropical Pacific and the ECT, respectively. As a cautionary note, the trend in the ECT, which is the strongest of the four regions, may be due to a combination of the strong impact of the 1997-1998 El Niño toward the end of the record, the lack of data before the shift in the mid-1970s, and the possible fresh bias in shipboard TSG data that may have been introduced in 1996-1998. With regard to the impact of the 1997-1998 El Niño, the trend is reduced in magnitude from -0.32 to -0.11 psu per 30 years if we do the computation ignoring 1997-1998.

[28] Figures 7 and 8 show a more comprehensive view of the long-term trends computed for each grip point along the PX05, PX12 and PX17 ship tracks. There is an overall tendency for downward trends along each track, with values less than $-0.25 \mathrm{psu}$ per 30 years $(=-0.008 \mathrm{psu} / \mathrm{yr})$ between about $10^{\circ} \mathrm{S}-25^{\circ} \mathrm{N}$ for PX05, west of the dateline for PX12, and north of $5^{\circ} \mathrm{S}$ for PX17. Upward trends of the order of +0.12 psu per 30 years $(=+0.004 \mathrm{psu} / \mathrm{yr})$ are found within $5^{\circ} \mathrm{S}-22^{\circ} \mathrm{S}$ for PX17, slightly to the north of the area of positive trend in zonally integrated salinity found in the tropical Pacific by Boyer et al. [2005]. This $5^{\circ} \mathrm{S}-22^{\circ} \mathrm{S}$ positive trend may however reflect the relative shortness (19 years) of the regional times series covering the 19791997 years only. As a sensitivity study, the trend becomes positive $(+0.08$ psu per 30 years) in Figure $6 \mathrm{~d}$ when computed over the 19 years period running from 1976 to 1994 rather than negative $(-0.32$ psu per 30 years $)$ when computed over the 29 years period running from 1975 to 2003. The data span is thus clearly a key factor affecting the quantification of trends, especially when sudden changes occur in the time series such as in the mid-1990s [see Weatherhead et al., 1998].

[29] To complete the description of long-term trends, Figure 9 shows time series of the amount of ocean surface covered by SSS values lower than 34.8 in the western equatorial Pacific $\left(10^{\circ} \mathrm{S}-5^{\circ} \mathrm{N}, 140^{\circ} \mathrm{E}-180^{\circ}\right)$ and lower than 35.0 in the SW Pacific $\left(24^{\circ} \mathrm{S}-10^{\circ} \mathrm{S}, 160^{\circ} \mathrm{E}-140^{\circ} \mathrm{W}\right)$. The limits of these two important regions were selected so that to assure a good data distribution (Figure 2). The 34.8 threshold was chosen as this isohaline adequately represents the zonal SSS front characterizing the eastern edge of the warm pool, and the 35.0 isohaline delimits the low-salinity water in the SPCZ from the high-salinity water in the southcentral tropical Pacific. Both regions exhibit an increase of the surface covered by low-SSS waters, these areas increasing by more than $50 \%$ from the beginning to the end of the record, with slopes of 1.8 and $1.2 \times 10^{6} \mathrm{~km}^{2}$ per 30 years for the equatorial and off-equatorial regions, respectively. These values correspond to about 4.9 and 3.2 degree $^{2}$ 

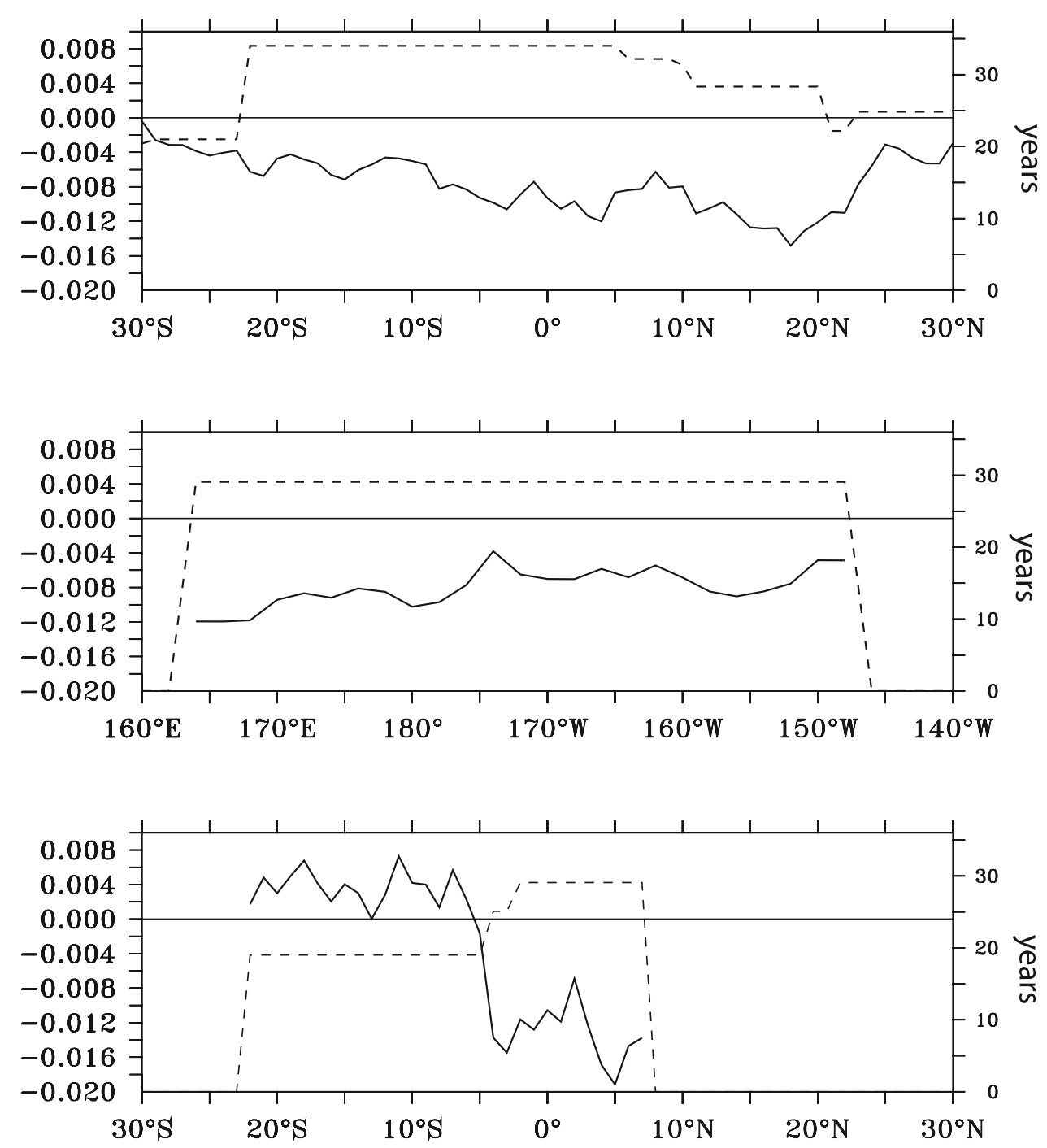

Figure 7. Linear trends in SSS (solid lines) along the (top) PX05, (middle) PX12, and (bottom) PX17 shipping tracks (units are psu/yr, scaled on the left axis) and record lengths of the corresponding times series (dashed lines; units are years, scaled on the left axis).

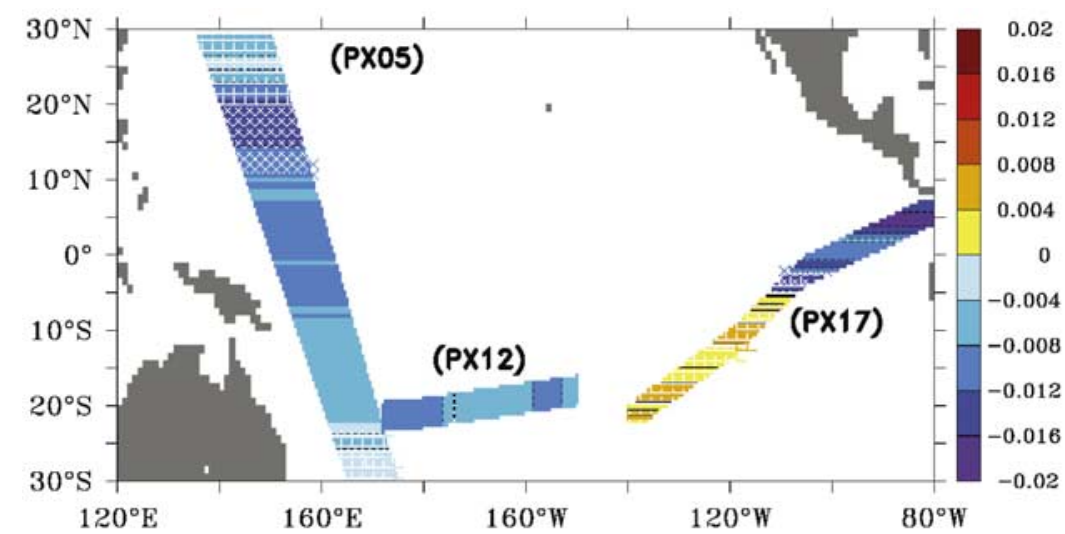

Figure 8. Linear trends in SSS along the PX05, PX12, and PX17 shipping tracks; units are psu/yr, scaled on the color bar. Lack of hatching denotes record lengths equal to or longer than 29 years; diagonal hatching is for 25-29 years; and vertical and horizontal hatching is for 19-24 years. 

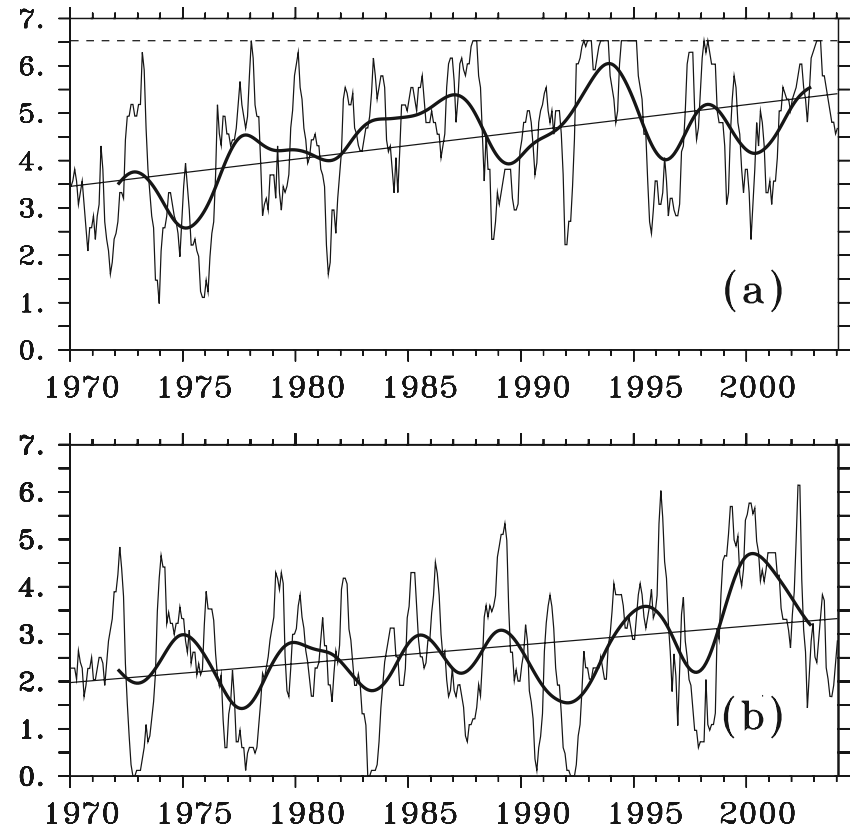

Figure 9. Monthly time series of the surface covered by (a) SSS lower than 34.8 in the $10^{\circ} \mathrm{S}-5^{\circ} \mathrm{N}, 140^{\circ} \mathrm{E}-180^{\circ}$ region and (b) SSS lower than 35.0 in the $24^{\circ} \mathrm{S}-10^{\circ} \mathrm{S}$, $140^{\circ} \mathrm{E}-140^{\circ} \mathrm{W}$ region. Units are $10^{6} \mathrm{~km}^{2}$. The lowfrequency curves in both plots represent the 61-month Hanning filtered values used to highlight SSS changes at periods longer than the ENSO timescale. The straight lines represent the linear least squares fits of the monthly values used to quantify linear trends. The horizontal line near 6.5 units in Figure 9a denotes the maximum possible covered surface (i.e., $40^{\circ}$ longitude $\times 15^{\circ}$ latitude).

latitude $\times$ longitude per year. In addition, we note a hint of a PDO-type signal in both time series. In particular, in the equatorial region, the area covered by SSS $<34.8$ tends to be below average before the mid-1970s, after the mid-1990s and during 1989-1990, and above average for the remaining time period.

[30] The decreasing trends in SSS we observed are qualitatively consistent with those inferred from coralderived $\delta \mathrm{O}_{18}$ records collected in the tropical Pacific (see Figure 2 and Table 1). The good agreement of these coralderived records with our instrumental records increases our confidence in the realism of the 1970-2003 SSS freshening, and suggests the freshening to be more than regional in scale.

\subsection{Possible Forcing Factors}

[31] Determining the factors that could induce long-term trend in SSS is a difficult problem, even qualitatively. Long time series of $\mathrm{P}$ and $\mathrm{E}$ are suspect for this purpose, and it is not possible to accurately calculate horizontal and vertical advection. Thus we attempt only to determine overall consistency between atmospheric forcing and oceanic response using available data sets and a survey of the published literature.

[32] Figure 10a shows the 1970-2003 linear trends in P derived from PREC. Downward trends appear as a horse- shoe pattern with maximum values located roughly in the ITCZ and SPCZ, while upward trends are found within about $5^{\circ} \mathrm{N}-15^{\circ} \mathrm{S}$ in the eastern half of the basin. As shown in Figure 10b, restricting the time period to 1979-2003 (as for CMAP and GPCP in Figures 10c and 10d) does not change the general pattern though maximum downward trends now appear centered on the equator near $165^{\circ} \mathrm{E}$. The CMAP product over the same period also portrays the horseshoe pattern with however enhanced negative values, especially in the ITCZ. Figures $10 \mathrm{a}-10 \mathrm{c}$ are overall consistent with calculations obtained from in situ rainfall measurements only, either over 1971-1990 [Morrissey and Graham, 1996] or 1970-2000 [Deser et al., 2004]. In contrast, a well-marked disagreement shows up when comparing the 1979-2003 trends derived from the GPCP (Figure 10d) and the three other products. The GPCP product, considered as the most reliable $\mathrm{P}$ product for trend calculation as it does not include atoll data [Yin et al., 2004], indicates significant upward P trends in the NW Pacific and in the region of the ITCZ and SPCZ, consistent with the response of global climate models forced by greenhouse gas emissions [Allen and Ingram, 2002]. As far as P only is concerned, trends from the PREC or CMAP products are totally inconsistent with our SSS trends (Figures 7 and 8). In contrast, trends from the GPCP product are qualitatively consistent in general with the SSS trends obtained along PX05 and PX12. Notable exceptions arise in the western equatorial Pacific (the equatorial parts of PX05) and in the SE Pacific (PX17) where other processes would have to be important (assuming the GPCP product is a reasonable representation of reality).

[33] The 1970-2003 E trends are shown in Figure 11 for the NCEP and ERA40 products. As noted for P trends, wellmarked qualitative and quantitative disagreements show up among these products, consistent with previous studies analyzing and comparing shorter E time series [Kubota et al., 2003; Feng and Li, 2006]. This prevents us from drawing robust conclusions about the potential role of $\mathrm{E}$ trend in driving SSS trends.

\section{Discussion and Conclusion}

[34] An analysis of 1970-2003 SSS data collected in the tropical Pacific enables us to detect PDO-type signals and long-term trends in three well-sampled regions: the western

Table 1. Sites With Coral-Derived $\delta 0_{18}$ Records Providing Information About Low-Frequency SSS Changes in the Tropical Pacific $^{\mathrm{a}}$

\begin{tabular}{lcc}
\hline \multicolumn{1}{c}{ Location } & Position & References \\
\hline Fiji & $17^{\circ} \mathrm{S}-179^{\circ} \mathrm{E}$ & $\begin{array}{c}\text { Le Bec et al. } \text { [2000]; } \\
\text { Juillet-Leclerc et al. }[2006]\end{array}$ \\
Guam & $13^{\circ} \mathrm{N}-145^{\circ} \mathrm{E}$ & Asami et al. [2005] \\
Maiana & $1^{\circ} \mathrm{N}-173^{\circ} \mathrm{E}$ & Urban et al. [2000] \\
Nauru & $1^{\circ} \mathrm{S}-166^{\circ} \mathrm{E}$ & Guilderson and Schrag [1999] \\
Palmyra & $5^{\circ} \mathrm{N}-162^{\circ} \mathrm{W}$ & Cobb et al. [2001] \\
Rarotonga & $21.5^{\circ} \mathrm{S}-160^{\circ} \mathrm{W}$ & Linsley et al. [2006] \\
Santo & $16^{\circ} \mathrm{S}-176^{\circ} \mathrm{E}$ & Kilbourne et al. [2004] \\
Secas Islands & $8^{\circ} \mathrm{N}-82^{\circ} \mathrm{W}$ & Linsley at al. $[1994]$ \\
Tarawa & $1^{\circ} \mathrm{N}-172^{\circ} \mathrm{E}$ & Cole et al. [1993] \\
\hline
\end{tabular}

${ }^{\mathrm{a}}$ See also Figure 2. 

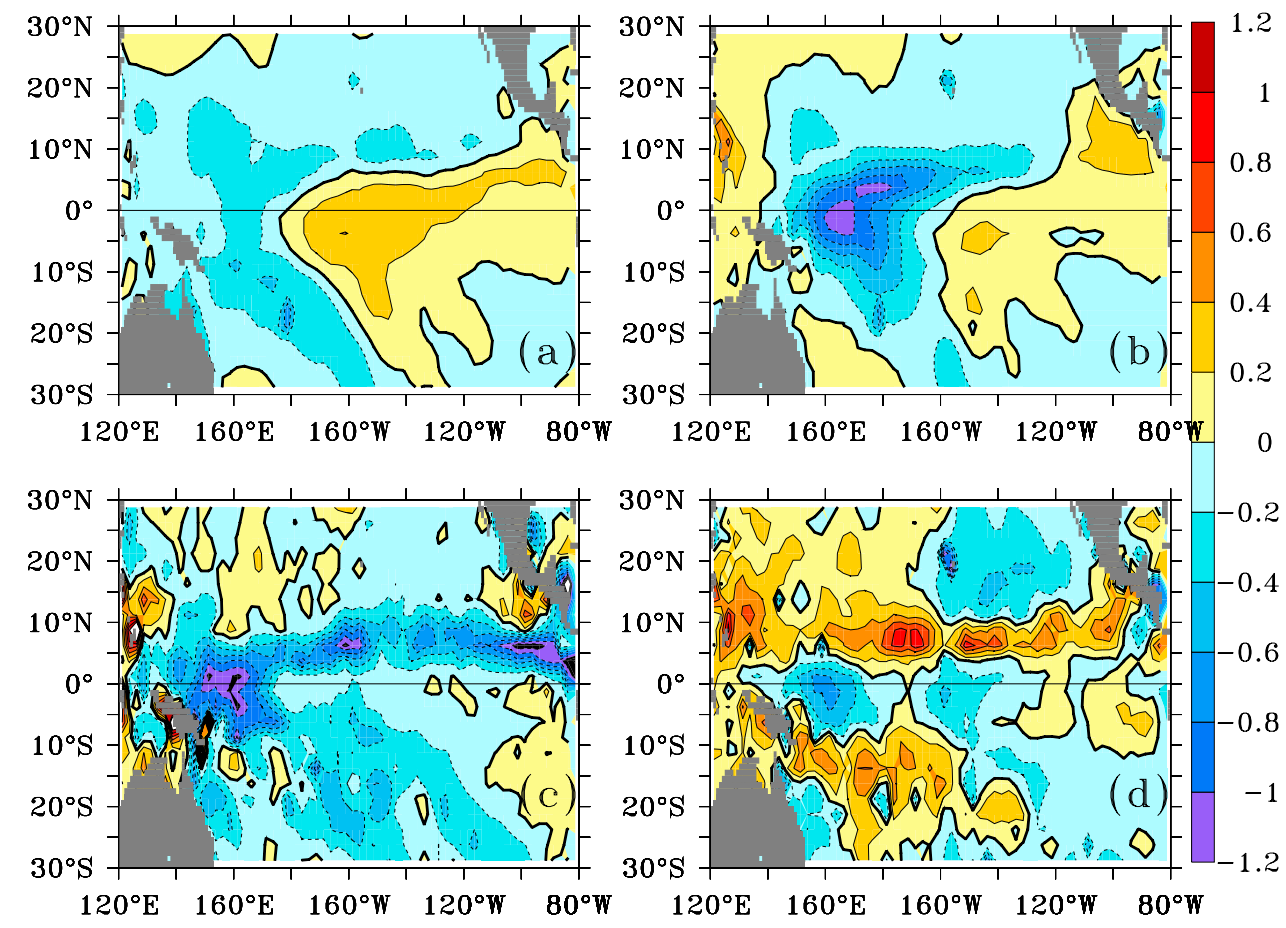

Figure 10. Comparison of precipitation trends computed from (top left) the PREC product over 19702003, (top right) the PREC product over 1979-2003, (bottom left) the CMAP product over 1979-2003, and (bottom right) the GPCP product over 1979-2003. See section 2 for details about the PREC, CMAP, and GPCP products. Contour intervals are 0.2 , and units are $\mathrm{m}$ after 30 years.

Pacific warm pool (WP), the SPCZ and the Equatorial Cold Tongue (ECT). PDO-type signals appeared as shifts in SSS appearing around the mid-1970s, mid-1990s, and to a lesser extent in 1989-1990. Specifically, except in the equatorial part of the WP, we found above-average SSS from the mid1970 s to the mid-1990s (except in 1989-1990), and belowaverage SSS before the mid-1970s and after the mid-1990s. Opposite changes took place for the equatorial part of the WP. In the WP and the SPCZ, these PDO-type SSS changes were found to be qualitatively consistent with precipitation, evaporation and/or horizontal and vertical circulation changes. In the ECT, the only possibility of explaining the SSS changes is horizontal advection. However, we were not able to assess the importance of this process in absence of adequate in situ data and published information.

[35] For the three well-sampled regions, we further documented notable decreasing trends in SSS of the order of 0.1 to 0.4 psu per 30 years. These decreases are related to an increasing trend of the ocean surfaces covered by lowsalinity waters in the WP (SSS < 34.8) and the SPCZ (SSS < 35.0). In searching for tentative explanations for these trends, we found qualitative agreement with trends in the GPCP precipitation product in the NW Pacific and in the heavy rainfall regions of the ITCZ and SPCZ. However, there were notable differences between the GPCP and both CMAP and PREC precipitation products, reinforcing conclusions from some recent studies that GPCP may be more suitable than CMAP and PREC for use in the analysis of low-frequency precipitation changes [Yin et al., 2004; Yaremchuk, 2006].

[36] The indication of a PDO-like signal in SSS in the WP, SPCZ and ECT, the evidence of SSS trends, as well as
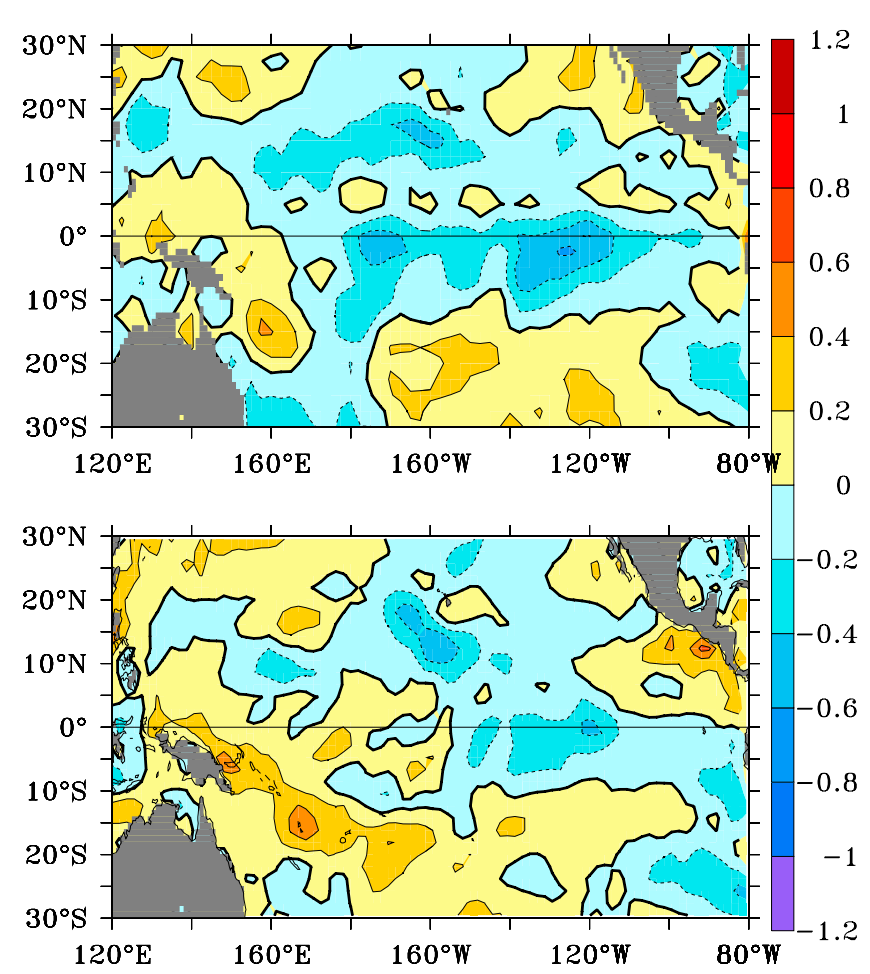

Figure 11. Comparison of evaporation trends computed from (top) the ERA40 product and (bottom) the NCEP product, both over 1970-2003. See section 2 for details about the ERA40 and NCEP products. Contour intervals are 0.2 , and units are $\mathrm{m}$ after 30 years. 
suggestions for forcing factors, have interesting repercussions regarding the link between ENSO and the PDO, the possible influence of ENSO on SSS trends, mixed-layer characteristics, and sea level changes. These issues are discussed below.

\subsection{ENSO and the PDO}

[37] Changes in SSS during El Niño (La Niña) events [see Delcroix, 1998, Plate 3b] show interesting similarities with those we detected during the positive (negative) phases of the PDO. The regression coefficients between the 19702003 SOI and P changes (not shown here) are similar to those shown in Figure 5. Horizontal advection has been shown to be a likely contributor to SSS changes in the WP and in the SPCZ at the ENSO timescales [Picaut et al., 1996; Gouriou and Delcroix, 2002]. Equatorial upwelling is enhanced in the ECT and has a surface signature as far west as PX05 during La Niña events [Delcroix et al., 1992; Sprintall and McPhaden, 1994]. Spot hydrographic observations and TAO/TRITON-derived continuous time series show that the EUC weakens or completely vanishes during El Niño events while it strengthens during La Niña events [Firing et al., 1983; Yu and McPhaden, 1999; Johnson et al., 2002; Izumo et al., 2002; Izumo, 2005]. The zonal tilt of the thermocline is enhanced (reduced) during La Niña (El Niño) events. Hence changes in SSS, P, horizontal and vertical advection during positive (negative) PDO periods are remarkably akin of those observed during El Niño (La Niña) periods. This agrees with Figure 4 showing that positive (negative) PDO periods clearly tend to be associated with more frequent El Niño (La Niña) events. Part of the PDO-like signal could thus be simply due to an increasing number or length of El Niño/La Niña events, an issue that is currently under debate [e.g., Rodgers et al., 2004b].

\subsection{ENSO and SSS Trends}

[38] It is tempting to attribute a large part of the increasing size of the region covered by low-salinity waters in the $10^{\circ} \mathrm{S}-5^{\circ} \mathrm{N}, 140^{\circ} \mathrm{E}-180^{\circ}$ region to the greater number of El Niño versus La Niña events that took place during the study period, since El Niño events produce a relative increase of the surface covered by low-SSS waters. This increase is evident for example in 1972-1973, 1976-1977, 1982-1983, 1986-1987, 1992-994, 1997-1998, and 2002 (Figure 9a). The opposite effects however apply for the SPCZ region (Figure 9b) where all El Niño events result in a decrease of the surface covered by low-SSS waters. Hence, despite the possible effects of El Niño, there are still positive trends in both regions signifying that the trends do not result directly from ENSO mechanisms.

\subsection{Mixed-Layer Characteristics}

[39] The trends in SSS result in noteworthy modifications of the surface layer as illustrated for the well sampled $10^{\circ} \mathrm{S}-5^{\circ} \mathrm{N}, 140^{\circ} \mathrm{E}-180^{\circ}$ region. In Figure 9a, we showed that the surface covered by low $(<34.8)$ SSS value has increased by about $50 \%$ from 1970 to 2003. A similar percentage is obtained for the surface covered by SST warmer than $29^{\circ} \mathrm{C}$ (not shown here), indicating that the warm and fresh pool expands over time. When computing the density changes resulting from the cumulative effects of
SSS and SST changes in that region, this results in a trend of $-0.013 \mathrm{~kg} \mathrm{~m}^{-3} \mathrm{yr}^{-1}$, in which about $60 \%$ are due to salinity. Computation of the 1970-1995 density trend for the same region, based on the independent temperature and salinity data described by Boyer et al. [2005], gives values of $-0.013,-0.010$, and $-4.10^{-4} \mathrm{~kg} \mathrm{~m}^{-3} \mathrm{yr}^{-1}$ for the 0,50 and $75 \mathrm{~m}$ depth levels, respectively. The decreasing density trend in this region thus chiefly occurs near the surface only, which should affect stratification across the base of the mixed layer. Surface density changes accumulated over two to three years are actually the same order of magnitude as the $0.03 \mathrm{~kg} \mathrm{~m}^{-3}$ threshold frequently used to estimate the depth of the mixed layer from a surface value [de Boyer Montégut et al., 2004].

\subsection{Sea Level Changes}

[40] Numerous papers show that correlation between sea level and surface dynamic height computed from temperature profile and mean $\mathrm{T} / \mathrm{S}$ curve is lower in the western tropical Pacific than elsewhere on seasonal to interannual timescales because of the influence of salinity changes [e.g., Busalacchi et al., 1994]. That salinity influence on sea level also applies at the PDO timescale and for long-time trend. As an example, for the WP where the near-surface temperature is of the order of $28^{\circ}-29^{\circ} \mathrm{C}$ and the SSS changes are generally representative of the upper 35 to $50 \mathrm{~m}$ [Cronin and McPhaden, 1998], the PDO-type signal converts into alternating sea level changes of the order of -3 to $+3 \mathrm{~cm}$ between the negative and positive phases of the PDO. Also, the trend in density computed in the above paragraph converts into an increase of sea level of about $2 \mathrm{~cm}$ over 30 years (for $h=35 \mathrm{~m}$ ), $1.2 \mathrm{~cm}$ of which would be due to salinity alone. This increases amounts to $33-66 \%(20-40 \%$ because of salinity alone) of the $1-2 \mathrm{~mm} \mathrm{yr}^{-1}$ global sea level change estimated from tide gauges over the last century [Church et al., 2001]. Hence the salinity contributions to sea level need to be considered when determining causes for the regional rate of sea level change and when discussing long-term sea level changes from altimetry measurements covering the last decade [Cazenave and Nerem, 2004].

[41] To conclude, our observations of a PDO-like signal and long-term trends in SSS raise a number of interesting issues. (1) The inability to derive quantitative conclusions regarding the driving mechanisms for SSS changes on decadal timescales emphasizes for the most part the lack of trustworthy $\mathrm{E}-\mathrm{P}$ products on these timescales. There is a clear need to improve these products, which perhaps may be aided by ongoing collection of in situ SSS data, as well as the future satellite-derived salinity and rainfall measurements [Kerr et al., 2001; Koblinsky et al., 2003]. It is important that our observed SSS signals be reproduced in climate models in order to gain confidence in simulated low-frequency changes, and improved products of both SSS and $\mathrm{E}-\mathrm{P}$ will help to establish the veracity of these signals. (2) The decreasing trends we found in SSS are opposite to those found for the tropical Atlantic [Curry et al., 2003; Boyer et al., 2005] while both tropical oceans experienced an increase in SST [Cane et al., 1997; Xue et al., 2003]. This underscores the complex relationship between SSS, SST and E - P changes that are worthy of further investigation as they relate to the global hydrological cycle. 
(3) The observed SSS freshening and SST warming trends constructively combine to reduce the near-surface density and, in doing so, induce a more stable and thinner mixedlayer depth, if we assume, as discussed above, that subsurface density changes are significantly smaller. This would tend to favor warmer SSTs, alter the ocean-atmosphere coupling strength and the character of ENSO and lowfrequency variability [Neelin, 1989; Maes et al., 2002]. (4) The PDO-related SSS and SST changes (Figures 4 and 5) are of same sign and so tend to compensate in density in the eastern equatorial Pacific cold tongue. On the basis of model results [see Harper, 2000], the possibility exists that these surface $\mathrm{T} / \mathrm{S}$ variations may be influenced by spiciness anomalies originating in the southeast Pacific extratropics that have made their way to the equator via a western boundary and/or interior pathway. It would be valuable to test this hypothesis from a comprehensive analysis of available in situ temperature and salinity profiles. (5) The SSS freshening trends we observed may reflect modifications of the hydrological cycle and/or oceanic circulation in response to global change. The question remains, however, as to whether our 1970-2003 freshening is part of a longer trend due to anthropogenic forcing or just part of a continuum of low-frequency natural variability. The interpretation of few $\delta \mathrm{O}_{18}$ coral records suggests that freshening in the Coral Sea started by the end of the 19th century [Hendy et al., 2002]. Additional paleoclimate indicators at multiple locations in the Pacific, the continuation and enhancement of the present in situ SSS monitoring system, and future global remotely sensed SSS observations will in combination help us to answer this question.

[42] Acknowledgments. We acknowledge the Sea Surface Salinity Observation Service (http://www.legos.obs-mip.fr/observations/sss/), the TAO Project Office (http://www.pmel.noaa.gov/tao/), the European Centre for Medium-Range Weather Forecasts (http://www.ecmwf.int/), the National Centers for Environment Prediction (http://www.cdc.noaa.gov/ncep reanalysis/), the Climate Prediction Center (http://www.cpc.ncep.noaa. gov/products/global_precip/html/web.html), the British Atmospheric Data Centre (http://badc.nerc.ac.uk/home/), and the National Oceanographic Data Center (http://www.nodc.noaa.gov/OC5/indprod.html) for providing free and open access through the World Wide Web to the data we use in this manuscript. The authors wish to acknowledge use of the Ferret program for analysis and graphics in this paper. Ferret is a product of NOAA's Pacific Marine Environmental Laboratory. (Information is available at http://ferret.pmel.noaa.gov/Ferret/.) This is PMEL publication 2970.

\section{References}

Adler, R., et al. (2003), The version-2 global precipitation climatology project (GPCP) monthly precipitation analysis (1979-present), J. Hydrometeorol., 4, 1147-1167.

Allen, M., and W. Ingram (2002), Constraints on future changes in climate and the hydrologic cycle, Nature, 419, 224-232, doi:10.1038/nature01092

Antonov, J. I., S. Levitus, and T. P. Boyer (2002), Steric sea level variations during 1957-1994: Importance of salinity, J. Geophys. Res., 107(C12), 8013, doi:10.1029/2001JC000964.

Asami, R., T. Yamada, Y. Iryu, T. M. Quinn, C. P. Meyer, and G. Paulay (2005), Interannual and decadal variability of the western Pacific sea surface condition for the years 1787-2000: Reconstruction based on stable isotope record from a Guam coral, J. Geophys. Res., 110, C05018, doi:10.1029/2004JC002555.

Blackman, R., and J. Tukey (1958), The Measurement of Power Spectra From the Point of View of Communication Engineering, 190 pp., Dover, Mineola, N. Y.

Boyer, T. P., S. Levitus, J. I. Antonov, R. A. Locarnini, and H. E. Garcia (2005), Linear trends in salinity for the World Ocean, 1955-1998, Geophys. Res. Lett., 32, L01604, doi:10.1029/2004GL021791.
Bratcher, A. J., and B. S. Giese (2002), Tropical Pacific decadal variability and global warming, Geophys. Res. Lett., 29(19), 1918, doi:10.1029/ 2002GL015191.

Busalacchi, A. J., M. J. McPhaden, and J. Picaut (1994), Variability in equatorial Pacific sea surface topography during the verification phase of the TOPEX/Poseidon mission, J. Geophys. Res., 99, 24,725-24,738.

Cabanes, C., A. Cazenave, and C. Le Provost (2001), Sea level rise during past 40 years determined from satellite and in situ observations, Science, 294, 840-842.

Cane, M., and M. Evans (2000), Do the tropics rule?, Science, 290, $1107-$ 1108 .

Cane, M., A. Clement, A. Kaplan, Y. Kushnir, D. Pozdnyakov, R. Seager, S. Zebiak, and R. Murtugudde (1997), Twentieth-century sea surface temperature trends, Science, 275, 957-960.

Cazenave, A., and R. S. Nerem (2004), Present-day sea level change: Observations and causes, Rev. Geophys., 42, RG3001, doi:10.1029/ 2003RG000139.

Chang, P., B. Giese, L. Ji, H. Seidel, and F. Wang (2001), Decadal change in the south tropical Pacific in a global assimilation analysis, Geophys. Res. Lett., 28, 3461-3464.

Chavez, F., J. Ryan, S. Lluch-Cota, and M. Niquen (2003), From anchovies to sardines and back: Multidecadal change in the Pacific ocean, Nature, 299, 217-221.

Chen, M., P. Xie, J. E. Janowiak, and P. A. Arkin (2004), Verifying the reanalysis and climate models outputs using a 56-year data set of reconstructed global precipitation paper presented at 14th AMS Conference on Applied Meteorology, Am. Meteorol. Soc., Seattle, Wash., 11-15 Jan.

Church, J., et al. (2001), Changes in sea level, in Climate Change 2001: The Scientific Basis, Contribution of Working Group 1 to the Third Assessment Report of the Intergovernmental Panel of Climate Change, edited by J. T. Houghton et al., pp. 639-693, Cambridge Univ. Press, N. Y. (Available at http://www.grida.no/climate/ipcc_tar/)

Cobb, K., C. Charles, and D. Hunter (2001), A central tropical Pacific coral demonstrates Pacific, Indian, and Atlantic decadal climate connections, Geophys. Res. Lett., 28, 2209-2212.

Cole, J., R. Fairbanks, and G. Shen (1993), Recent variability in the Southern Oscillation: Isotopic results from a Tarawa Atoll coral, Science, 260, $1790-1793$

Corrège, T., M. Gagan, W. Beck, G. Burr, G. Cabioch, and F. Le Cornec (2004), Interdecadal variation in the extent of South Pacific tropical waters during the Younger Dryas event, Nature, 428, 927-929.

Cronin, M., and M. McPhaden (1998), Upper ocean salinity balance in the western equatorial Pacific, J. Geophys. Res., 103, 27,567-27,587.

Curry, R., B. Dickson, and I. Yashayaev (2003), A change in the freshwater balance of the Atlantic Ocean over the past four decades, Nature, 426, $826-828$.

de Boyer Montégut, C., G. Madec, A. S. Fischer, A. Lazar, and D. Iudicone (2004), Mixed layer depth over the global ocean: An examination of profile data and a profile-based climatology, J. Geophys. Res., 109, C12003, doi:10.1029/2004JC002378.

Delcroix, T. (1998), Observed surface oceanic and atmospheric variability in the tropical Pacific at seasonal and ENSO time scales: A tentative overview, J. Geophys. Res., 103, 18,611-18,633.

Delcroix, T., and G. Eldin (1995), Observations hydrologiques dans l'Océan Pacifique tropical ouest campagnes SURTROPAC 1 à 17 , de janvier 1984 à août 1992, campagnes COARE156 1 à 3, d'août 1991 à octobre 1992, TDM 141, 78 pp., ORSTOM, Paris.

Delcroix, T., and C. Hénin (1991), Seasonal and interannual variations of sea-surface salinity in the tropical Pacific Ocean, J. Geophys. Res., 96, $22,135-22,150$

Delcroix, T., and M. McPhaden (2002), Interannual sea surface salinity and temperature changes in the western Pacific warm pool during 19922000, J. Geophys. Res., 107(C12), 8002, doi:10.1029/2001JC000862.

Delcroix, T., and J. Picaut (1998), Zonal displacement of the western equatorial Pacific fresh pool, J. Geophys. Res., 103, 1087-1098.

Delcroix, T., G. Eldin, M. H. Radenac, J. Toole, and E. Firing (1992), Variations of the western equatorial Pacific ocean, 1986-1988, J. Geophys. Res., 97, 5423-5447.

Delcroix, T., M. J. McPhaden, A. Dessier, and Y. Gouriou (2005), Time and space scales for sea surface salinity in the tropical oceans, Deep Sea Res. Part I, 52(5), 787-813, doi:10.1016/j.dsr.2004.11.012.

Deser, C., M. Alexander, and M. Timlin (1999), Evidence for a wind-driven intensification of the Kuroshio extension from the 1970s to the 1980s, J. Clim., 12, 1697-1706.

Deser, C., A. Phillips, and J. Hurrell (2004), Pacific interdecadal climate variability: Linkages between the tropics and the north Pacific during boreal winter since 1900, J. Clim., 17, 3109-3124.

Dickson, R., J. Meincke, S.-A. Malmberg, and A. J. Lee (1988), The "Great Salinity Anomaly" in the northern North Atlantic, Prog. Oceanogr., 20, $103-151$ 
Eldin, G., T. Delcroix, and M. Rodier (2004), The frontal area at the eastern edge of the western equatorial Pacific warm pool in April 2001, J. Geophys. Res., 109, C07006, doi:10.1029/2003JC002088.

Evans, M. N., M. A. Cane, D. P. Schrag, A. Kaplan, B. K. Linsley, R. Villalba, and G. M. Wellington (2001), Support for tropically-driven Pacific decadal variability based on paleoproxy evidence, Geophys. Res Lett., 28, 3689-3692.

Fedorov, A., and G. Philander (2000), Is El Niño changing?, Science, 288, 1997-2002.

Feng, L., and J. Li (2006), A comparison of latent heat fluxes over global oceans for ERA and NCEP with GSSTF2, Geophys. Res. Lett., 33 , L03810, doi:10.1029/2005GL024677.

Firing, E., R. Lukas, J. Sadler, and K. Wyrtki (1983), Equatorial undercurrent disappears during the 1982-1983 El Niño, Science, 222, 1121 1123.

Giese, B. S., S. C. Urizar, and N. S. Fučkar (2002), Southern Hemisphere origins of the 1976 climate shift, Geophys. Res. Lett., 29(2), 1014, doi:10.1029/2001GL013268.

Glantz, M. (1996), Currents of Change: El Niño's Impact on Climate and Society, 194 pp., Cambridge Univ. Press, New York.

Goddard, L., and M. Dilley (2005), El Niño: Catastrophe or opportunity?, J. Clim., 18, 651-665.

Gouriou, Y., and T. Delcroix (2002), Seasonal and ENSO variations of sea surface salinity and temperature in the South Pacific Convergence Zone during 1976-2000, J. Geophys. Res., 107(C12), 3185, doi:10.1029/ 2001JC000830.

Gu, D., and G. Philander (1997), Interdecadal climate fluctuations that depend on exchanges between the tropics and extratropics, Science, $275,805-807$.

Guilderson, T., and D. Schrag (1998), Abrupt shift in subsurface temperatures in the tropical Pacific associated with changes in El Niño, Science, $281,240-243$.

Guilderson, T., and D. Schrag (1999), Reliability of coral isotope records from the western Pacific warm pool: A comparison using age-optimized records, Paleoceanography, 14, 457-464.

Hare, S. (1996), Low frequency climate variability and salmon production, Ph.D. dissertation, 306 pp., Univ. of Wash., Seattle.

Hare, S., and N. Mantua (2000), Empirical evidence for North Pacific regime shifts in 1977 and 1989, Prog. Oceanogr., 47, $103-146$.

Harper, S. (2000), Thermocline ventilation and pathways of tropical-subtropical water mass exchange, Tellus, Ser. A, 52, 330-345.

Hendy, E., M. Gagan, C. Alibert, M. McCulloch, J. Lough, and P. Isdale (2002), Abrupt decrease in tropical sea surface salinity at end of Little Ice Age, Science, 295, 1511-1514

Hisard, P., Y. Magnier, and B. Wauthy (1969), Comparison of the hydrographic structure of equatorial waters north of New Guinea and at $170^{\circ} \mathrm{E}$, J. Mar. Res., 27, 191-205.

Huang, B., V. Metha, and N. Schneider (2005), Oceanic response to idealized net atmospheric freshwater in the Pacific at the decadal time scale, J. Phys. Oceanogr., 35, 2486-2647.

Izumo, T. (2005), The equatorial undercurrent, meridional overturning circulation, and their roles in mass and heat exchanges during El Niño events in the tropical Pacific Ocean, Ocean Dyn., 55, 110-123, doi.10.1017/ s10236-005-0115-1.

Izumo, T., J. Picaut, and B. Blanke (2002), Tropical pathways, equatorial undercurrent variability and the 1998 La Niña, Geophys. Res. Lett. 29(22), 2080, doi:10.1029/2002GL015073

Juillet-Leclerc, A., S. Thiria, P. Naveau, T. Delcroix, N. Le Bec, D. Blamart, and T. Corrège (2006), SPCZ migration and ENSO events during the 20th century as revealed by climate proxies from a Fiji coral, Geophys. Res. Lett., 33, L17710, doi:10.1029/2006GL025950.

Johnson, G., B. Sloyan, W. Kessler, and K. McTaggart (2002), Direct measurements of upper ocean currents and water properties across the tropical Pacific during the 1990s, Prog. Oceanogr., 52, 31-61.

Kalnay, E., et al. (1996), The NCEP/NCAR 40-year reanalysis project, Bull. Am. Meteorol. Soc., 77, 437-471.

Karspeck, A., and M. Cane (2002), Tropical Pacific 1976-77 climate shift in a linear, wind-driven, model, J. Phys. Oceanogr., 32, 2350 2360 .

Kerr, Y., P. Waldteufel, J. P. Wigneron, J. M. Martinuzzi, J. Font, and M. Berger (2001), Soil moisture retrieval from space: The Soil Moisture and Ocean Salinity (SMOS) mission, IEEE Trans. Geosci. Remote Sens., 39(8), 1729-1735.

Kessler, W. S. (1999), Interannual variability of the subsurface high salinity tongue south of the equator at $165^{\circ} \mathrm{E}, J$. Phys. Oceanogr., 29, $2038-$ 2049 .

Kessler, W. (2006), The circulation of the eastern tropical Pacific: A review, Prog. Oceanogr., 69, 181-217.
Kilbourne, K. H., T. M. Quinn, F. W. Taylor, T. Delcroix, and Y. Gouriou (2004), El Niño-Southern Oscillation-related salinity variations recorded in the skeletal geochemistry of a Porites coral from Espiritu Santo, Vanuatu, Paleoceanography, 19, PA4002, doi:10.1029/2004PA001033.

Kleeman, R., J. McCreary, and B. Klinger (1999), A mechanism for generating ENSO decadal variability, Geophys. Res. Lett., 26, 1743-1746.

Knutson, T. R., and S. Manabe (1998), Model assessment of decadal variability and trends in the tropical Pacific Ocean, J. Clim., 11, 2273-2296.

Koblinsky, C. J., P. Hildebrand, D. LeVine, F. Pellerano, Y. Chao, W. Wilson, S. Yueh, and G. Lagerloef (2003), Sea surface salinity from space: Science goals and measurement approach, Radio Sci., 38(4), 8064, doi:10.1029/2001RS002584.

Kubota, M., A. Kano, H. Muramatsu, and H. Tomita (2003), Intercomparison of various surface latent heat flux fields, J. Clim., 16, 670-678.

Latif, M. (1998), Dynamics of interdecadal variability in coupled oceanatmosphere models, J. Clim., 11, 602-624.

Le Bec, N., A. Juillet-Leclerc, T. Correge, D. Blamart, and T. Delcroix (2000), A coral $\delta^{18} \mathrm{O}$ record of ENSO driven sea surface salinity variability in Fiji (south-western tropical Pacific), Geophys. Res. Let., 27, $3897-3900$

Lehodey, P., F. Chai, and J. Hampton (2003), Modelling climate-related variability of tuna populations from a coupled ocean-biogeochemical populations dynamical model, Fish. Oceanogr., 12, 483-494.

Levitus, S., J. Antonov, T. Boyer, and C. Stephens (2000), Warming of the world ocean, Science, 287, 2225-2229.

Linsley, B. K., R. B. Dunbar, G. M. Wellington, and D. A. Mucciarone (1994), A coral-based reconstruction of intertropical convergence zone variability over Central America since 1707, J. Geophys. Res., 99, 99779994.

Linsley, B. K., A. Kaplan, Y. Gouriou, J. Salinger, P. B. deMenocal, G. M. Wellington, and S. S. Howe (2006), Tracking the extent of the South Pacific Convergence Zone since the early 1600s, Geochem. Geophys. Geosyst., 7, Q05003, doi:10.1029/2005GC001115.

Lukas, R. (2001), Freshening of the upper thermocline in the North Pacific subtropical gyre associated with decadal changes in rainfall, Geophys. Res. Lett., 28, 3485-3488.

Lukas, R., and E. Lindstrom (1991), The mixed layer of the western equatorial Pacific Ocean, J. Geophys. Res., 96, 3343-3358.

Maes, C. (1998), Estimating the influence of salinity on sea level anomaly in the ocean, Geophys. Res. Lett., 25, 3551-3554.

Maes, C., J. Picaut, and S. Belamari (2002), Salinity barrier layer and onset of El Niño in a Pacific coupled model, Geophys. Res. Lett., 29(24), 2206, doi:10.1029/2002GL016029.

Maes, C., J. Picaut, Y. Kuroda, and K. Ando (2004), Characteristics of the convergence zone at the eastern edge of the Pacific warm pool, Geophys. Res. Lett., 31, L11304, doi:10.1029/2004GL019867.

Mann, M. E., and J. Park (1994), Global-scale modes of surface temperature variability on interannual to century timescales, J. Geophys. Res., 99 $25,819-25,834$

Mann, M., R. Bradley, and M. Hughes (1999), Northern Hemisphere temperatures during the past millennium: Interferences, uncertainties, and limitations, Geophys. Res. Lett., 26, 759-762.

Mantua, N., and S. Hare (2002), The Pacific Decadal Oscillation, J. Oceanogr., 58, 35-44.

Mantua, N., S. Hare, Y. Zhang, J. Wallace, and R. Francis (1997), A Pacific interdecadal climate oscillation with impacts on salmon productions, Bull. Am. Meteorol. Soc., 78, 1069-1079.

McCreary, J. (1981), A linear stratified ocean model of the equatorial undercurrent, Philos. Trans. R. Soc. London, Ser. A, 298, $603-635$.

McCreary, J., and P. Lu (1994), Interaction between the subtropical and the tropical equatorial ocean circulations: The subtropical cell, J. Phys. Oceanogr., 24, 466-497.

McPhaden, M. J. (1981), Continuously stratified models of the steady state equatorial ocean, J. Phys. Oceanogr., 11, 337-354.

McPhaden, M. J., and D. Zhang (2002), Slowdown of the meridional overturning circulation in the upper Pacific Ocean, Nature, 415, 603-608.

McPhaden, M. J., et al. (1998), The Tropical Ocean Global Atmosphere (TOGA) observing system: A decade of progress, J. Geophys. Res., 103, $14,169-14,240$

Minobe, S., T. Manabe, and A. Shouji (2002), Maximal wavelet filter and its application to bidecadal oscillation over the Northern Hemisphere through the twentieth century, J. Clim., 15, 1064-1075.

Morrissey, M., and N. Graham (1996), Recent trends in rain gauge precipitation measurements from the tropical Pacific: Evidence for an enhanced hydrologic cycle, Bull. Am. Meteorol. Soc., 77, 12071219.

Neelin, J. D. (1989), Interannual oscillations in an ocean general circulation model coupled to a simple atmosphere model, Philos. Trans. R. Soc London Ser A, 329,189-205. 
Nitta, T., and S. Yamada (1989), Recent warming of tropical sea surface temperature and its relationship to the Northern Hemisphere circulation, J. Meteorol. Soc. Jpn., 67, 375-383.

Overland, J., and I. Salo (1999), Salinity signature of the Pacific decadal oscillation, Geophys. Res. Lett., 26, 1337-1340.

Peterson, W. T., and F. B. Schwing (2003), A new climate regime in northeast Pacific ecosystems, Geophys. Res. Lett., 30(17), 1896, doi:10.1029/ 2003GL017528.

Philander, S. G. H. (1990), El Niño, La Niña and the Southern Oscillation, 289 pp., Elsevier, New York.

Picaut, J., M. Ioualalen, C. Menkes, T. Delcroix, and M. McPhaden (1996), Mechanism of the zonal displacements of the Pacific Warm Pool: Implications for ENSO, Science, 274, 1486-1489.

Picaut, J., M. Ioualalen, T. Delcroix, F. Masia, R. Murtugudde, and J. Vialard (2001), The oceanic zone of convergence on the eastern edge of the Pacific Warm Pool: A synthesis of results and implications for ENSO and biogeochemical phenomena, J. Geophys. Res., 106, $2363-$ 2386.

Pierce, D., T. Barnett, and M. Latif (2002), Connections between the Pacific Ocean tropics and midlatitudes on decadal timescales, J. Clim., 13, $1173-1194$

Power, S., T. Casey, C. Folland, A. Coleman, and V. Metha (1999), Interdecadal modulation of the impact of ENSO on Australia, Clim. Dyn., 15 $319-324$

Qiu, B., and T. Joyce (1992), Interannual variability in the mid- and lowlatitude western North Pacific, J. Phys. Oceanogr., 22, 1062-1079.

Rayner, N. A., D. E. Parker, E. B. Horton, C. K. Folland, L. V. Alexander, D. P. Rowell, E. C. Kent, and A. Kaplan (2003), Global analyses of sea surface temperature, sea ice, and night marine air temperature since the late nineteenth century, J. Geophys. Res., 108(D14), 4407, doi:10.1029/ 2002JD002670.

Rodgers, K. B., O. Aumont, G. Madec, C. Menkes, B. Blanke, P. Monfray, J. C. Orr, and D. P. Schrag (2004a), Radiocarbon as a thermocline proxy for the eastern equatorial Pacific, Geophys. Res. Lett., 31, L14314, doi:10.1029/2004GL019764.

Rodgers, K., P. Friedrichs, and M. Latif (2004b), Tropical Pacific decadal variability and its relation to decadal modulations of ENSO, J. Clim., 17, $3761-3774$.

Schneider, N. (2000), A decadal spiciness mode in the tropics, Geophys. Res. Lett., 27, 257-260.

Smith, T., and D. Reynolds (2003), Extended reconstruction of global sea surface temperatures based on COADS data (1854-1997), J. Clim., 16 , $1495-1510$.

Sprintall, J., and M. J. McPhaden (1994), Surface layer variations observed in multiyear time series measurements form the western equatorial Pacific, J. Geophys. Res., 99, 963-979.

Timmermann, A., and F. Jin (2002), A nonlinear mechanism for decadal El Niño amplitude changes, Geophys. Res. Lett., 29(1), 1003 doi:10.1029/2001GL013369.
Tourre, Y., B. Rajagopalan, Y. Kushnir, M. Barlow, and W. White (2001), Patterns of coherent decadal and interdecadal climate signals in the Pacific during the 20th century, Geophys. Res. Lett., 28, 2069-2072.

Trenberth, K. (1984), Signal versus noise in the southern oscillation, Mon. Weather Rev., 112, 326-332.

Trenberth, K. E. (1990), Recent observed interdecadal climate changes in the Northern Hemisphere, Bull. Am. Meteorol. Soc., 71, 988-993.

Urban, F., J. Cole, and J. Overpeck (2000), Influence of mean climate change on climate variability from a 155-year tropical Pacific coral record, Nature, 407, 989-993.

Wang, B., and S. I. An (2001), Why the properties of El Niño changed during the late 1970s, Geophys. Res. Lett., 28, 3709-3712.

Wang, B., and S. I. An (2002), A mechanism for decadal changes of ENSO behavior: Roles of background wind changes, Clim. Dyn., 18, 475-486, doi:10.1007/s00382-001-0189-5.

Wang, C., and J. Picaut (2004), Understanding ENSO physics-A review, in Earth's Climate: The Ocean-Atmosphere Interaction, Geophys. Monogr. Ser., vol. 147, edited by C. Wang, S.-P. Xie, and J. A. Carton, pp. 21-48, AGU, Washington, D. C.

Weatherhead, E. C., et al. (1998), Factors affecting the detection of trends: Statistical considerations and applications to environmental data, J. Geophys. Res., 103, 17,149-17,162.

World Climate Research Program (1985), Scientific plan for the TOGA program, World Clim. Res. Program Publ. Ser. 3, Geneva, Switzerland, Sept.

Xie, P., and P. Arkin (1997), Global precipitation: A 17-year monthly analysis based on gauge observations, satellite estimates, and numerical model outputs, Bull. Am. Meteorol. Soc., 78, 2539-2558.

Xue, Y., T. Smith, and R. Reynolds (2003), Interdecadal changes of 30-yr normals during 1871-2000, J. Clim., 16, 1601-1612.

Yaremchuk, M. (2006), Sea surface salinity constrains rainfall estimates over tropical oceans, Geophys. Res. Lett., 33, L15605, doi:10.1029/ 2006GL026582.

Yasunaka, S., and K. Hanawa (2005), Regime shifts and El Niño/Southern Oscillation events in the global sea surface temperatures, Int. J. Climatol., 25, 913-930, doi:10.1002/joc.1172.

Yin, X., A. Gruber, and P. Arkin (2004), Comparison of the GPCP and CMAP merged gauge-satellite monthly precipitation products for the periods 1979-2001, J. Hydrometeorol., 5, 1207-1222.

Yu, X., and M. J. McPhaden (1999), Dynamical analysis of seasonal and interannual variability in the equatorial Pacific, J. Phys. Oceanogr., 29 , $2350-2369$

S. Cravatte and T. Delcroix, UMR 5566, LEGOS, IRD, 14, avenue Ed Belin, F-31400 Toulouse, France. (thierry.delcroix@ird.fr)

M. J. McPhaden, PMEL, NOAA, 7600 Sand Point Way NE, Seattle, WA 98115, USA. 